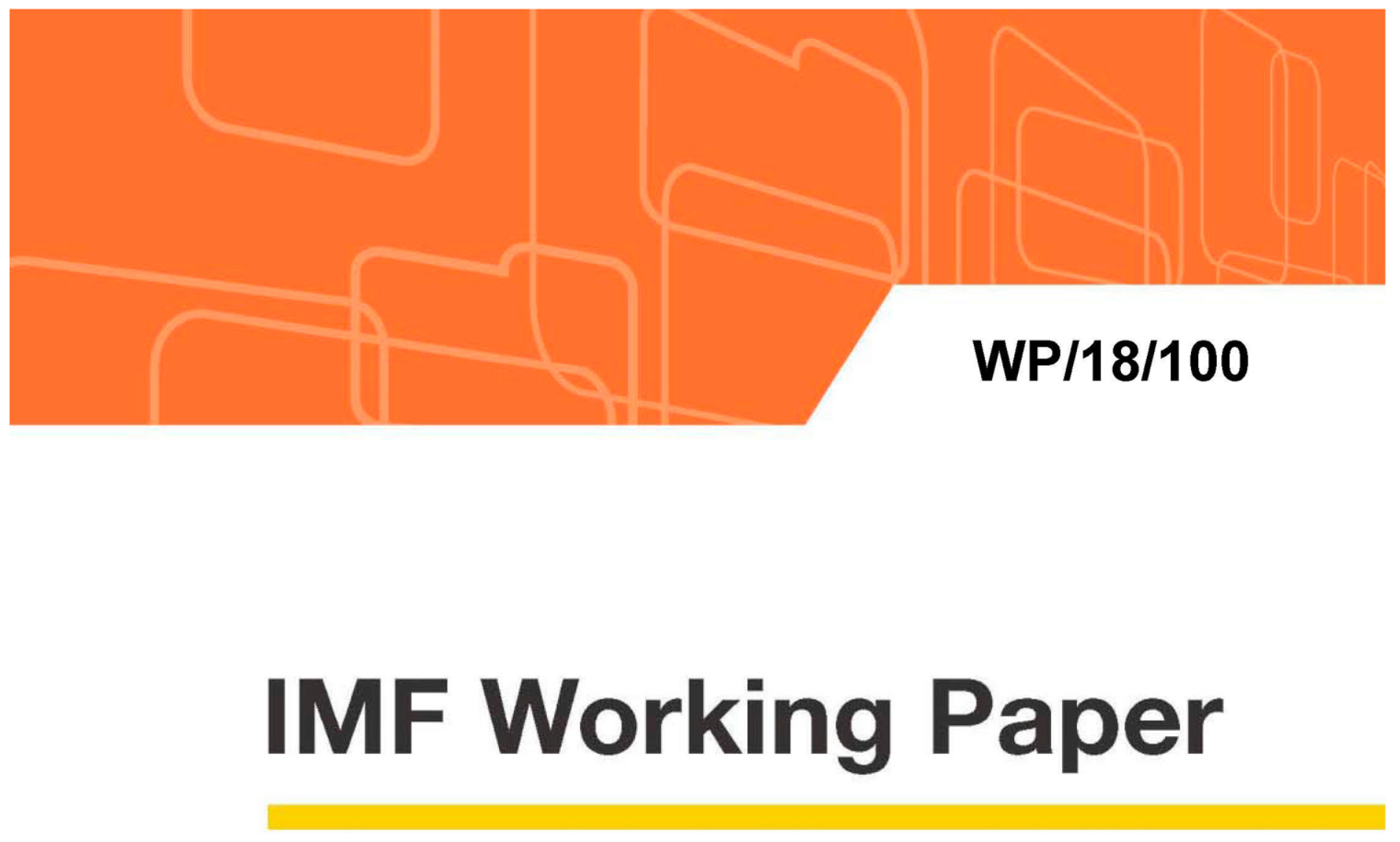

\title{
Real Sectoral Spillovers: A Dynamic Factor Analysis of the
} Great Recession

by Nan Li and Vance Martin

IMF Working Papers describe research in progress by the author(s) and are published to elicit comments and to encourage debate. The views expressed in IMF Working Papers are those of the author(s) and do not necessarily represent the views of the IMF, its Executive Board, or IMF management.

$$
\text { I N T E R N A T I O N A L M O N E T A R Y F U N D }
$$




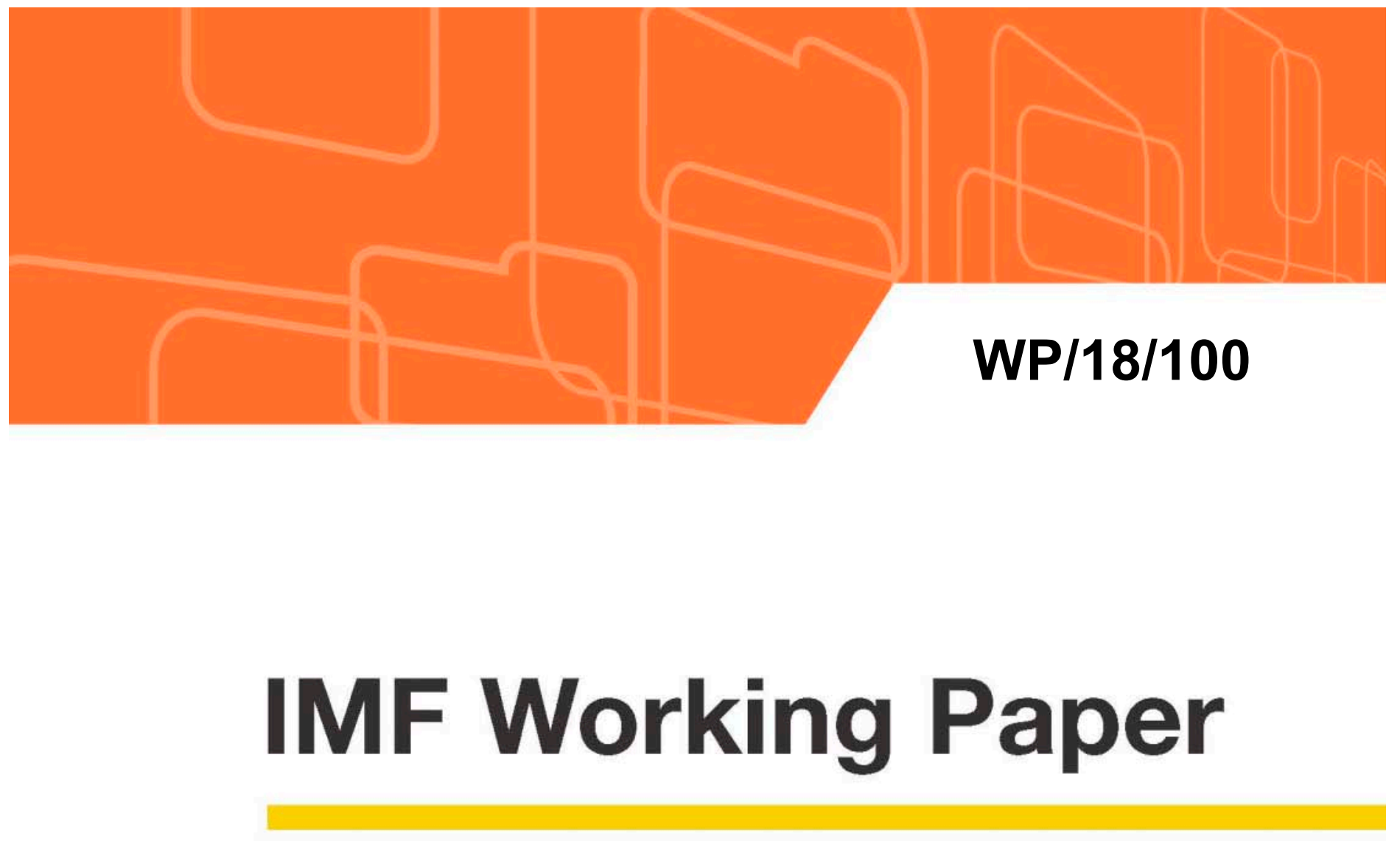

\section{Real Sectoral Spillovers: A Dynamic Factor Analysis of the Great Recession}

by Nan Li and Vance Martin

IMF Working Papers describe research in progress by the author(s) and are published to elicit comments and to encourage debate. The views expressed in IMF Working Papers are those of the author(s) and do not necessarily represent the views of the IMF, its Executive Board, or IMF management.

$$
\text { I N T E R N A T I O N A L M O N E T A R Y F U N D }
$$




\title{
IMF Working Paper
}

Research Department

\section{Real Sectoral Spillovers: A Dynamic Factor Analysis of the Great Recession \\ * Prepared by Nan Li and Vance Martin}

Authorized for distribution by Luis Cubeddu

May 2018

\section{IMF Working Papers describe research in progress by the author(s) and are published to elicit comments and to encourage debate. The views expressed in IMF Working Papers are those of the author(s) and do not necessarily represent the views of the IMF, its Executive Board, or IMF management.}

\begin{abstract}
This paper studies changes in the transmission of common versus sectoral idiosyncratic shocks across different U.S. nonfarm business sectors during the Great Recession, and evaluates the cross-sectoral spillovers. Shocks are identified by dynamic factor methods. We find that the Great Recession is largely a time of heightened impact of common shockswhich accounts for 3/4 of aggregate volatility - and large spillovers of negative financerelated shocks. Moreover, in contrast with the earlier literature that failed to find a significant role of sectoral shocks (propagated through the input-output linkages across sectors) in driving variability in aggregate industry output, this study allows spillovers of shocks to operate through other mechanisms intertemporally. We find that prior to the recession the majority of aggregate fluctuations is explained by sector-specific shocks.
\end{abstract}

JEL Classification Numbers: C32, C67, E32, E23

Keywords: Intersectoral Linkages, Dynamic Factor Models, Spillovers, Real Business Cycles, Input-output Structure.

Authors’ E-Mail Addresses: nli@imf.org, vance@unimelb.edu.au

\footnotetext{
* We are grateful to Vasco Carvalho, Bill Dupor, Yuriy Gorodnichenko, Pierre-Daniel Sarte, and seminar participants at Australian National University, University of Melbourne, International Monetary Fund, the Australian and New Zealand Econometrics Study Group, Society of Economic Dynamics, Econometric Society Meeting for many helpful suggestions and comments.
} 


\section{Introduction}

The source of economic fluctuations occupies a salient position in the collective imagination of economic theorists and empiricists. Traditional thoughts view economic cycles being driven by sizable exogenous shocks that impact upon all sectors and firms simultaneously. More recently, a burgeoning strand of research substantiated the belief that aggregate fluctuations can originate from shocks at the micro level which may not "average out" in the presence of interconnections between different sectors or firms (e.g. Acemoglu et al., 2013; Acemoglu et al., 2012; Carvalho, 2014; Carvalho and Gabaix, 2011; Di Giovanni et al., 2014; Foester et al., 2011; Gabaix, 2012). Many believe that the recent Great Recession is a manifestation of the propagation of negative shocks stemming from disaggregated sectors to the rest of the economy. For example, the construction sector has been argued to be an important driver of aggregate output dynamics in the U.S. through its input-output (I-O) linkages and demand complementarity with other goods (Bodrin et al., 2013). Other theories of the crisis attribute the economic decline to the failure of the financial sectors (e.g. Brunnnermeier and Sannikov, 2013; Christiano et al., 2009, amongst many others).

Understanding sector-specific and common sources of economic fluctuations is undeniably important for potential policy design. For instance, it informs the recent policy debate over the ripple effects of bailing out or subsidizing distressed sectors (such as financial or auto industries). Whether the nature of the transmission mechanism accords with different perceptions merits a rigorous econometric investigation. Existing empirical studies on the role of sector-specific shocks, however, have only considered industrial production sectors. The leading analysis by Foerster et al. (2011; FSW, henceforth) finds that these shocks only play a modest role in aggregate variability, even when the propagation of shocks are explicitly taken into account through the I-O linkages. However, Carvalho and Gabaix (2011) point out that including service sectors is crucial when studying cross-sectoral movements. This point is especially relevant for studying the recent Great Recession. In addition, in order to identify idiosyncratic sectoral shocks for the large number of sectors (117 disaggregated industrial sectors) FSW need to rely exclusively on factor demand linkages - which can be readily estimated from the I-O matrix and capital-flow matrix - to propagate idiosyncratic shocks. Such an approach limits the sectoral interactions to the specific production channel and may underestimate the overall impact of idiosyncratic shocks.

Using production data of sixteen 2-3 digit U.S. private sectors - including both goods-producing and service-providing sectors - from 1948 to 2016, this paper examines in detail the transmission of sectoral idiosyncratic shocks and evaluates the spillover relationships across all nonfarm business sectors in the economy. We focus on changes of these shocks versus common shocks in contributing to aggregate volatility during the Great Recession. Like FSW, we employ dynamic factor 
methods to extract the unobserved aggregate and idiosyncratic sectoral shocks from sectoral output growth. Different from their method, however, we allow shocks to propagate intertemporally through channels other than factor-demand linkages. In addition, we distinguish between an underlying fundamental aggregate shock which affects all sectors throughout the entire sample period and an additional common shock which emerged only during the Recession. To properly assess the relative importance of sector-specific versus common shocks, we also allow the volatilities of the sector-specific shocks to change during the Recession-backed by an empirical test showing that there was a break. The identified common and idiosyncratic shocks are then evaluated according to their contribution to the forecast variance of other sectors and to aggregate volatility.

The incorporation of the second common factor that arose during the Recession, as well as shifts in the volatilities of sectoral shocks, are motivated by the observation that there was a significant change in the economy over the period. The aggregate annual growth rate dropped from 3.4 percent per year to 0.2 percent, whereas aggregate volatility doubled its pre-crisis value. Similar observations apply to most of the disaggregated sectors. Also evident in Figure I is the more diverse distribution of growth correlations across sector-pairs associated with the Recession. While growth in some sectors became more negatively correlated with growth in others, the majority of the sectors comoved even more. Overall, the correlations increased from a pre-2007 average of 0.26 to a post-2007 average of 0.45 , suggesting additional linkages occur during the crisis period. ${ }^{1}$

A simple decomposition analysis shows that aggregate variability is largely driven by covariability across sectors, not sectoral shocks to the few sectors with large weights in aggregate output. These large sectors, however, can potentially play an important role as they often provide a large share of inputs in the production of downstream sectors or have strong complementarities with other sectors. Productivity disturbances originating in these sectors can drive up the covariability among sectors, with significant aggregate consequences. Theoretically, the aggregate contribution of a sector-specific shock depends on both the size of the shock and its direct and indirect spillover relationships with other sectors. To empirically evaluate the contribution of individual sectoral shocks on the broader economy requires proper identification of idiosyncratic and common shocks first and foremost.

\footnotetext{
${ }^{1}$ The average cross-sectoral correlation using annual data is even higher at almost 0.60 , showing higher degree of comovement than previous crises (see Section 6 for more details). However, as pointed out in Forbes and Rigobon (2002), an increase in correlation during a crisis is neither necessary nor sufficient for the presence of additional linkages relating markets because an increase in correlation can arise simply from an increase in sectoral volatility without any change in the fundamental linkages connecting markets. However, the empirical analysis conducted below shows strong evidence of an additional common factor operating during the Great Recession, while the relative sizes of the sectoral factors appear to be stable across regimes. In addition, the emergence of a significant additional common factor is found to be unique for the Great Recession and did not arise in a similar fashion during the earlier crises.
} 
Ideally, one would like to adopt a completely "agnostic approach" by empirically estimating the spillovers across sectors without assuming any specific synchronization mechanism. Unfortunately, identification of shocks requires imposing at least some structure on the contemporary or intratemporal propagation mechanism. Our empirical strategy is to consider a "hybrid approach": we estimate the intra-temporal transmission parameters using the U.S. I-O table and capital flow table in a way that is consistent with neoclassical multisector growth models, while simultaneously identifying dynamic or inter-temporal spillovers (or at least part of them) from the data, without a priori restrictions on the structure of the latter. Based on the estimated model, we then employ the Diebold-Yilmaz (2009) decomposition which allows us to split the forecast error variances of output growth in each sector into components attributable to the various sources of shocks. This method helps us to gauge the spillover effects between each sector-pair and identify the sectors that have the largest impact on the rest of the economy. To gain additional insight, we further contrast our results with the "structural approach" in which the parameters governing the contemporary and dynamic transmission mechanisms in the factor model are both directly constructed using the U.S. I-O and capital flow tables (as in FSW). Such a comparison allows us to evaluate the adequacy of input linkages in transmitting shocks.

Our analysis shows that the Great Recession was largely a time of heightened impact of common shocks and large spillover of negative finance-related shocks. The additional common factor that emerged during the recession explains $3 / 4$ of aggregate volatility, and is the dominant determinant of sectoral interconnectedness as measured by the Diebold-Yilmaz decomposition. Robustness checks also show that the emergence of this additional common factor is unique for the period of the Great Recession and did not arise during earlier crisis periods. Inspecting the estimated matrix of forecast variance decomposition across sectors (the share of 3-year-ahead error variance in forecasting output growth in sector $i$ due to shocks to sector $j$ ) reveals that the "Finance and insurance" sector has the largest spillover effects on other sectors, followed by the "Nondurable manufacturing" sector.

How important are the effects of sector-level disturbances on the aggregate economy depends on the extent to which sectors are interconnected. In contrast to previous findings that the majority of the variability of aggregate industrial production prior to the Great Recession is explained by common shocks, our analysis shows that by allowing for additional linkages connecting sectors other than input-output and capital flows, the Hybrid model finds that sector-specific shocks actually account for the majority of aggregate volatility prior to the Recession. In contrast however, all of the structural models investigated show that the common shock still plays the dominant role in determining aggregate volatility even after extending the analysis to include service-providing 
sectors. The advantages of allowing sectoral shocks to propagate dynamically through channels other than factor demand linkages is highlighted by the empirical result that the Hybrid model is able to capture the cross-sectoral correlations much better than the structural approaches.

Our work draws on and contributes to the literature studying the microeconomic underpinnings of aggregate fluctuations. An important strand of research explores disaggregated sectoral data to evaluate the impact of micro-level vs. macro-level shocks, such as Atalay (2017), FSW (2011), Conley and Dupor (2003), Shea (2002), Horvath (1998), Dupor (1999) and Forni and Reichlin (1998). This paper builds on FSW (2011) who demonstrate that a class of neoclassical multisector models with input-output structures produces a dynamic factor model as a reduced form. As our paper analyzes the spillover relationships not only between industrial sectors but also service sectors, we are working with a smaller number of and more aggregated sectors. This choice allows us to estimate empirically the dynamic transmission of shocks cross sectors in addition to the propagation along I-O linkages. Such tradeoffs mark the difference between this paper and FSW, and allow us to gain additional insight on the adequacy of I-O linkages in understanding the propagation of sectoral shocks. Related, Ando (2014) applies the FSW approach to all sectors including service and agriculture sectors and finds that focusing only on industrial production sectors leads to a potential bias of $10-45 \%$ in the contribution of sectoral shocks.

In terms of methodologies, our dynamic factor approach combines two strands of literature: the recent spillover literature (Diebold and Yilmaz, 2009) where the dynamics are modeled using a VAR with structural shocks identified by imposing contemporaneous restrictions on the linkages amongst the shocks, and the contagion literature (Dungey et al. 2010) where additional factors are identified during crisis periods which do not operate during noncrisis periods. In contrast to the factor structure of SVAR models, a special feature of this model is that the number of factors exceeds the dimension of the VAR with the factors consisting of sector-specific factors, common factors that operate throughout the whole period, as well as additional aggregate factors that operate just during the Recession. To identify the additional common factor the strategy is to divide the log-likelihood into two regimes, yielding additional moments thereby providing additional information to identify linkages arising during the crisis. A similar approach is adopted in the monetary shocks literature such as Sacks and Rigobon $(2003,2004)$ and Craine and Martin (2008).

The rest of the paper proceeds as follows. Section 2 provides a first check of the data on the sectoral output for 16 U.S. nonfarm business sectors. Section 3 specifies the dynamic factor model and Section 4 discusses the estimation issues and provides the key empirical results from our analysis. Section 5 compares the results from alternative modeling strategies. A number of 
robustness checks are summarized in Section 6 with details of the results presented in Appendix C.3. Section 7 concludes.

\section{U.S. Sectoral Output of Nonfarm Business Sectors}

\subsection{Data Statistics}

Annual and quarterly observations on real output for 16 nonfarm private sectors are obtained from the U.S. Bureau of Economic Analysis (BEA) (1947-2016), with quarterly data available from 2005Q1. Most sectors are broadly-defined 2-digit level NAICS sectors except when there is a meaningful disaggregation for the question at hand, then the lower-level sectors are considered (e.g., we separate Durable Manufacturing from the Nondurable Manufacturing sector, and Finance and Insurance from Real Estate and Rental). The annual growth rate (in percentage points) in sector $i$ at time $t$ is defined as $y_{i t}=100 \times \ln \left(Y_{i t} / Y_{i t-1}\right)$, and the year-on-year growth rate using quarterly data is given by $y_{i, t}^{q}=100 \times \ln \left(Y_{i, t}^{q} / Y_{i, t-4}^{q}\right)$. The input use table from the BEA provides the value of inputs in producer prices used by each industry for 136 sectors. We aggregate the sectors up and construct a 16-sector I-O matrix and capital flow matrix. More details of the data are relegated to Appendix A.

The list of the 16 sectors and their summary statistics on annual growth rates are presented in Table I for the total period (1948-2016), together with the sub-period prior to the Great Recession (1948-2006) (pre-GR) and during the Recession (2007-2012) (GR). The mean growth rates for most sectors more than halved during the crisis, with some of the sectors experiencing negative growth rates. The only exception is the Mining sector which exhibits increases in its average growth rate from $1.1 \%$ to $2.6 \%$. Associated with the general falls in sectoral growth rates during the Great Recession are increases in volatility, with the standard deviation of growth increasing in 10 out of the 16 sectors and most noticeably in the Wholesale Trade sector and Durables Manufacturing sector.

The first glimpse at the time series of sectoral output growth shows that the downfall of the Construction and the Real Estate sectors preceded the recession, which would suggest that these sectors provided the initial spark for the crisis. On the other hand, it was the Durables Manufacturing and Wholesale Trade sectors that had the sharpest declines in their output growth. Given their relative size this may suggest an important role for these sectors in the aggregate economy. However, concluding, based on these casual observations, that shocks to these sectors are the ultimate cause of the collapse of economic activity would be problematic, because (a) sector-specific versus common shocks have yet been identified and the relative magnitude of these shocks needs 
to be estimated, and (b) the linkages between these sectors and the rest of the economy might not be strong enough to allow disruptions to these sectors to have a large quantitative impact on the aggregate economy. In the following sections, we will investigate in detail the implications of the sector share distribution, intersectoral linkages on aggregate volatility, and identify and evaluate the impacts of different shocks.

\subsection{Sectoral Size, Covariability and Linkages}

Recent work by Gabaix (2011), amongst others, raises the question as to whether aggregate fluctuations are mainly associated with idiosyncratic and mutually uncorrelated shocks to sectors with large shares. As a first pass, following earlier works in this area (e.g. FSW 2011, Shea 2002), we approximate the aggregate growth by a weighted average of disaggregated sectoral growth rates, i.e. $y_{t} \cong \sum_{i=1}^{N} w_{i} y_{i t}$, where $w_{i}$ is sector $i$ 's time-invariant average share in aggregate output (see the last column in Table I), and decompose the aggregate variance into a term due to individual sector's own volatility and a term due to covariation across all sectors: $\sigma_{y}^{2}=\sum_{i} w_{i}^{2} \sigma_{y_{i}}^{2}+\sum_{i \neq j} w_{i} w_{j} \operatorname{cov}\left(y_{i}, y_{j}\right)$.

First, we find that it is covariability amongst sectors, not sector-specific variability, that explains aggregate variability. Specifically, the covariance term in the above decomposition explains $70 \%$ of the aggregate volatility during the whole sample period, and has contributed more during the Great Recession (74\% compared to $64 \%$ pre-recession), suggesting the possibility of an additional factor or a set of factors operating during this period. Second, when replacing the sector-specific weight $w_{i}$ by an equal weight of $1 / N$, the calculated aggregate volatility tracks closely the actual volatility. Thus, aggregate volatility is not mainly driven by independent shocks to a small number of sectors with relatively large shares. However, this latter finding does not necessarily imply that sectoral size does not matter for understanding aggregate variability. In fact, evaluating the importance of sectoral sizes and sectoral covariability separately could be misleading, as they both are endogenous outcomes to the structure of the economy and are not independent of each other. Potentially, any intersectoral linkages giving rise to covariability between sectors might also cause some sectors to grow larger than others, as these linkages are heterogeneous.

To better illustrate this point, let us consider a specific type of intersectoral linkage that has been widely studied in the literature and can be easily measured in the data - the input-output linkages across sectors. Shocks to "central sectors" in the input-output network - sectors that provide important inputs (directly or indirectly) to downstream sectors - are transmitted pervasively to the rest of the economy, causing high covariability across sectors. Thus, they have a disproportionate effect on aggregate output. Below, we show that this "centrality" characteristics of a sector is highly correlated with its size both theoretically and empirically. We measure centrality by the 
"influence factor", which quantifies the relative importance of each sector as an intermediate input in production to all sectors in the economy.

For a variant of the multisector model of Long and Plosser (1983), the aggregate output growth $\left(y_{t}\right)$ can be expressed as a linear combination of sectoral productivity growth $\left(z_{j t}\right)$ with coefficients determined by the "influence factor" $v_{j}$ (see Appendix B for details):

$$
y_{t}=\sum_{j=1}^{N} v_{j} z_{j t} .
$$

The influence factor, $v_{j}$, depends on the consumption expenditure share of sector- $j$ product (denoted by $\theta_{j}$ ) and its overall contribution as an input supplier in the production of all $N$ sectors of the economy $\left(\sum_{i=1}^{N} v_{i} \gamma_{j i}\right.$, where $\gamma_{j i}$ represents the cost share of the input from sector $j$ in sector $i$.):

$$
v_{j}=\theta_{j}+\sum_{i=1}^{N} v_{i} \gamma_{j i},
$$

Theoretically, $v_{j}$ is the same as gross output share and hence the influence factor in fact equals the relative size of a sector in this simple model.

Using the BEA 2002 input-use table which provides estimates for $\Gamma=\left[\gamma_{j i}\right]_{N \times N}$ and $\boldsymbol{\theta}=\left[\theta_{i}\right]_{N \times 1}$, we calculate $v_{i}$ for all 16 sectors based on $\boldsymbol{v}=\left(I_{N}-\Gamma\right)^{-1} \boldsymbol{\theta}$, and compare it with the sectoral size $\left(w_{i}\right)$ in Figure A.1. A strong and positive relationship between the estimated influence factor of a given sector and its relative size is observed both for the case of heterogeneous consumption shares (Figure A.1(a)) and for the case of equal consumption shares (Figure A.1(b)). Large sectors (such as Professional and business services, Finance and insurance, and Durable and Nondurable goods manufacturing sectors) are also important intermediate input suppliers and have high influence factors. Because of their "centrality" in the input-output network, shocks hitting large sectors are transmitted into other sectors pervasively, driving the covariation of sectoral growth rates, the predominant source of variations in aggregate output. Since sectoral sizes and covariability are interrelated concepts, it is potentially problematic to evaluate the importance of sectoral sizes and sectoral covariability as competing driving forces for aggregate variability.

Furthermore, assume sectoral productivity shocks can be decomposed into a component common to all sectors, $a_{t}$, and a mutually independent sector-specific component, $\xi_{j t}: z_{j t}=\lambda_{j} a_{t}+\xi_{j t}$, where $\lambda_{j}$ governs the sensitivity of sector $j$ to the common shock. Equation (1) implies that the aggregate 
volatility $\left(\sigma_{y}^{2}\right)$ can be expressed as:

$$
\sigma_{y}^{2}=\left(\sum_{j=1}^{N} v_{j} \lambda_{j}\right)^{2} \sigma_{a}^{2}+\sum_{j=1}^{N} v_{j}^{2} \sigma_{\xi_{j}}^{2} .
$$

Equation (3) implies that to evaluate the contribution of sectoral fluctuations to the overall economy requires understanding the intersectoral linkages in the economy (as captured by $v_{j}$ ) and proper identification of common and sector-specific idiosyncratic shocks, including estimation of their volatilities $\left(\sigma_{a}, \sigma_{\xi_{j}}\right)$ and the loadings $\left(\lambda_{j}\right)$. When the size of the common shock is relatively large, or when central sectors are more sensitive to the common shock (i.e. high $\left(\sum_{j=1}^{N} v_{j} \lambda_{j}\right)$ ), common shocks can play a large role. On the other hand, when large sector-specific shocks hit central sectors, sectoral shocks can also contribute significantly to aggregate volatility. While these shocks are not directly observed in the data, in the following sections we adopt dynamic factor methods to extract them from sectoral output growth.

\section{A Dynamic Factor Model of Sectoral Output}

In this section an $N$-dimensional dynamic factor model of sectoral output growth for the U.S. is specified. The building blocks of the model are based on a structural vector autoregression (SVAR) model with three special features. The first is the inclusion of an additional common factor that captures additional sectoral linkages operating during the Great Recession. The second feature is designed to capture volatility changes during the Great Recession that are idiosyncratic to sectoral shocks. The third is to allow for a set of empirical cross-sectoral linkages - which are overlaid on the SVAR model specification - to identify all $N^{2}$ contemporaneous transmission parameters of sectoral shocks throughout the economy. Formally, identification of these transmission mechanisms is achieved by including additional structural information arising from input-output linkages in a way that is in line with neoclassical multisector growth models.

Let $y_{t}$ represent a $(N \times 1)$ vector containing the percentage growth rates of real sectoral output whose statistics are given in Table I. The dynamics of $y_{t}$ are assumed to have the following general form of a vector autoregressive moving average (VARMA) representation:

$$
\mathbf{y}_{t}=\Phi \mathbf{y}_{t-1}+\Pi_{0} \varepsilon_{t}+\Pi_{1} \varepsilon_{t-1},
$$

where $\Phi$ is a $(N \times N)$ matrix of autoregressive parameters, $\Pi_{0}$ is a $(N \times N)$ contemporaneous parameters and $\Pi_{1}$ are $(N \times N)$ matrix of moving average parameters. ${ }^{2}$ The model captures the

\footnotetext{
${ }^{2}$ The VARMA model in (4) is specified with one lag, but can be easily extended to allow for longer lags. In the
} 
intertemporal dynamical sectoral interlinkages as well as the transmission of structural shocks to all $N$ sectors in the economy within the same period. The $(N \times 1)$ disturbance vector $\varepsilon_{t}$ is assumed to have zero mean and heteroskedastic covariance matrix $\Omega_{t}$ to be specified below, $\varepsilon_{t} \sim\left(0, \Omega_{t}\right)$.

The generality of the VARMA model in (4) means that not all of the parameters of the model can be identified without imposing some additional structure on the model. There are two identification issues. The first is the identification of aggregate and sectoral shocks while also allowing for the presence of additional shocks during the Great Recession. The second is the identification of all $N^{2}$ propagation mechanisms of the $N$ sectoral shocks.

\subsection{Aggregate and Sector-Specific Shocks}

To identify aggregate and sectoral shocks over the sample period $T$, two regimes are specified: the period prior to the Great Recession $\left(T_{1}\right)$, and the period of the Great Recession $\left(T_{2}\right)$, with $T=T_{1}+T_{2}$.

The set of VAR disturbances $\varepsilon_{t}$ in (4) is decomposed into an aggregate shock $a_{t}$, which impacts upon all components of $\varepsilon_{t}$ simultaneously with sector-specific loadings $\lambda_{i}$, and a set of sector-specific shocks $\left(\eta_{i t}\right)_{i=1,2, \cdots, N}$ with loadings $\sigma_{i}$ during the pre-GR period and loadings $\omega_{i}$ during the Great Recession. Moreover, an additional common factor $c_{t}$ is also included during the Great Recession with loadings $\delta_{i}$ to help capture the observed increases in sectoral volatility. We thereby call $c_{t}$ the 'GR factor' from hereon. These choices of factor dimensions are examined later by conducting some pre-testing of the model's factor structure.

The relationships between the VAR disturbances $\varepsilon_{t}=\left(\varepsilon_{1 t}, \varepsilon_{2 t}, \cdots, \varepsilon_{N t}\right)$ in $(4)$ and the $N+2$ structural shocks $u_{t}=\left(a_{t}, \eta_{1 t}, \eta_{2 t}, \cdots, \eta_{N t}, c_{t}\right)$, are formally defined over the two regimes as:

$$
\varepsilon_{i t}= \begin{cases}\lambda_{i} a_{t}+\sigma_{i} \eta_{i t} & : t \in T_{1} \\ \lambda_{i} a_{t}+\omega_{i} \eta_{i t}+\delta_{i} c_{t} & : \quad t \in T_{2}\end{cases}
$$

The common shock $a_{t}$, operates over the entire period with its impact on the $N$ sectors during the pre-GR and GR periods assumed to be the same. Equation (5) allows for two sources of increased volatility that characterize the Great Recession. The first arises from the GR factor $c_{t}$, if $\delta_{i}$ is significantly different from zero. The second source comes from increases in volatility from the sectoral factors $\eta_{i t}$, if $\omega_{i}>\sigma_{i}$. The difference in the sectoral parameters over the two regimes represents the effects of structural breaks which are tested in the empirical analysis later. The

empirical application the specification of the model is augmented to include a vector of intercepts as well as variables to capture the peaks and troughs of the U.S. business cycle and the period of the Great Moderation. 
contemporaneous factor structure of $\varepsilon_{t}$ across the two regimes is conveniently summarized as

$$
\varepsilon_{t}=S_{i} u_{t}, \quad t \in T_{i}
$$

where the structural disturbance factors in vector $u_{t}$ are assumed to be independently distributed and normalized to have zero mean and unit variance, i.e. $u_{t} \sim$ iid $(0, I)$. The parameter matrices $S_{i}, i=1,2$, contain the factor loading parameters for the pre-GR and GR periods respectively, which according to (5) have the following structures:

$$
S_{1}=\left[\begin{array}{cccccc}
\lambda_{1} & \sigma_{1} & & & & 0 \\
\lambda_{2} & & \sigma_{2} & & & 0 \\
\vdots & & & \ddots & & \vdots \\
\lambda_{N} & & & & \sigma_{N} & 0
\end{array}\right], \quad S_{2}=\left[\begin{array}{cccccc}
\lambda_{1} & \omega_{1} & & & \delta_{1} \\
\lambda_{2} & & \omega_{2} & & \\
\vdots & & & \ddots & & \vdots \\
\lambda_{N} & & & & \omega_{N} & \delta_{N}
\end{array}\right]
$$

Using (6) in (4), we rewrite the SVAR model in terms of the structural shocks $u_{t}$ as:

$$
\mathbf{y}_{t}=\Phi \mathbf{y}_{t-1}+\Pi_{0} S_{i} u_{t}+\Pi_{1} S_{i} u_{t-1}, \quad i=1,2 .
$$

Given the properties of the structural shocks $\left(u_{t}\right)$, the VAR disturbance covariance matrix for the two periods is decomposed as:

$$
\Omega_{t}=E\left[\varepsilon_{t} \varepsilon_{t}^{\prime}\right]=\left\{\begin{array}{lll}
\Omega_{1}=S_{1} S_{1}^{\prime} & : & t \in T_{1} \\
\Omega_{2}=S_{2} S_{2}^{\prime} & : & t \in T_{2}
\end{array}\right.
$$

where

$$
\Omega_{1}=\left[\begin{array}{cccc}
\lambda_{1}^{2}+\sigma_{1}^{2} & \lambda_{1} \lambda_{2} & \cdots & \lambda_{1} \lambda_{N} \\
\lambda_{2} \lambda_{1} & \lambda_{2}^{2}+\sigma_{2}^{2} & \cdots & \lambda_{2} \lambda_{N} \\
\vdots & \vdots & \ddots & \vdots \\
\lambda_{N} \lambda_{1} & \lambda_{N} \lambda_{2} & \cdots & \lambda_{N}^{2}+\sigma_{N}^{2}
\end{array}\right]
$$

and

$$
\Omega_{2}=\left[\begin{array}{cccc}
\lambda_{1}^{2}+\omega_{1}^{2}+\delta_{1}^{2} & \lambda_{1} \lambda_{2}+\delta_{1} \delta_{2} & \cdots & \lambda_{1} \lambda_{N}+\delta_{1} \delta_{N} \\
\lambda_{2} \lambda_{1}+\delta_{2} \delta_{1} & \lambda_{2}^{2}+\omega_{2}^{2}+\delta_{2}^{2} & \cdots & \lambda_{2} \lambda_{N}+\delta_{2} \delta_{N} \\
\vdots & \vdots & \ddots & \vdots \\
\lambda_{N} \lambda_{1}+\delta_{N} \delta_{1} & \lambda_{N} \lambda_{2}+\delta_{N} \delta_{2} & \cdots & \lambda_{N}^{2}+\omega_{N}^{2}+\delta_{N}^{2}
\end{array}\right]
$$

The diagonal elements of $\Omega_{1}$ and $\Omega_{2}$ represent the relative contributions of the underlying aggregate factor, the sectoral factors and the GR factor to sectoral volatility in each of the two sub-periods. The off-diagonal terms are the covariances, which show that the instantaneous con- 
nectedness amongst sectors are determined by the aggregate factor $\left(\lambda_{i} \lambda_{j}\right)$ during the pre-GR period and a combination of the underlying aggregate factor and the GR factor $\left(\lambda_{i} \lambda_{j}+\delta_{i} \delta_{j}\right)$ during the Great Recession. Prior to the recession, positive (negative) covariances occur when the effects of aggregate shocks on sectoral output have the same (opposite) signs. A similar result occurs for both $a_{t}$ and $c_{t}$ during the period of the Great Recession except that now the overall sign is determined by the relative strengths of the two common shocks.

\subsection{Hybrid Model Identification}

An important feature of the model in (4) is that shocks specific to particular sectors $\left(\eta_{i t}\right)$ can be propagated throughout the entire economy in a way that generates cross-sector covariability with the strength of the contemporaneous spillovers captured by the off-diagonal elements of the matrix $\Pi_{0}$. Unfortunately, within the standard SVAR framework at most $N(N+1) / 2$ linkages between the VAR disturbances $\varepsilon_{t}$ in (4) and the structural shocks $u_{t}$ in (6) can be identified as a result of the symmetry property of the covariance matrix of $\varepsilon_{t}$. Without further information, it is not possible to identify all $N^{2}$ potential contemporaneous linkages amongst the $N$ structural shocks on the $N$ sectors. $^{3}$

To circumvent the identification restrictions of standard SVAR models, the approach is to make use of the structural multi-sectoral growth model presented in FSW, in which both output production and capital goods in a given sector are produced using other sectors' output (see Appendix B.1 for details of the model specifications). The structural parameters of the model (denoted by $\vartheta)$, include parameters governing household's time preference $(\beta)$, capital's depreciation rate $\left(\delta_{d}\right)$, the capital share of production in various sectors $\left(\varphi=\left[\varphi_{i}\right]_{N \times 1}\right)$, the intermediate input-use ma$\operatorname{trix}\left(\Gamma=\left[\gamma_{i j}\right]_{N \times N}\right)$ and the capital-use matrix $\left(\Psi=\left[\psi_{i j}\right]_{N \times N}\right)$. That is, $\vartheta=\left\{\beta, \delta_{d}, \varphi, \Gamma, \Psi\right\}$. The matrices $\Gamma$ and $\Psi$ can be quantified using the U.S. BEA estimates of the input-use table and capital flow table, respectively. Sector-specific capital shares are calculated as value added minus labor compensation divided by sectoral gross output using the same input-use table. The other parameters take values standard in the literature at an annual frequency: $\beta=0.96$ and $\delta_{d}=0.1$.

An important feature of the FSW structural model is that as it admits a VARMA representation of the form given in (8), in which $\Pi_{0}$ and $\Pi_{1}$ are simply functions of $\vartheta$ and thus can be identified using calibrated values of $\vartheta$. It is also possible to quantify the $\Phi$ matrix within the FSW framework, but the approach here is to leave $\Phi$ unrestricted and allow for a potentially broader range of additional

\footnotetext{
${ }^{3}$ Formally the covariance matrix of the VAR in the case where there is no moving average term $\left(\Theta_{1}=0\right)$ is given by $E\left(\Pi_{0} \varepsilon_{t} \varepsilon_{t}^{\prime} \Pi_{0}^{\prime}\right)=E\left(\Pi_{0} S_{i} S_{i}^{\prime} \Pi_{0}^{\prime}\right), i=1,2$, where $S_{i}$ contains the unknown parameters associated with the aggregate, idiosyncratic and GR factors. This expression shows that $\Pi_{0}$ and $S_{i}$ are determined jointly from the same set of moments as given by the VAR residuals covariance matrix. Clearly it is not possible to identify all of the elements in the two matrices making it necessary to impose some restrictions on the model.
} 
potential linkages that are not only production based. We later compare the results with that of the FSW structural approach. ${ }^{4}$

Assuming that the matrix polynomial $\left(I_{N}+\Pi_{1} \Pi_{0}^{-1} L\right)$ is invertible, we rewrite the model in (4) as the following VAR representation:

$$
\left(I_{N}+\Pi_{1} \Pi_{0}^{-1} L\right)^{-1}\left(I_{N}-\Phi L\right) \mathbf{y}_{t}=\Pi_{0} S_{i} u_{t}, \quad i=1,2 .
$$

As a first order approximation to this system the lag length is truncated at the first lag: ${ }^{5}$

$$
\mathbf{y}_{t}=\left(\Phi+\Pi_{1} \Pi_{0}^{-1}\right) \mathbf{y}_{t-1}+\Pi_{0} S_{i} u_{t}, \quad i=1,2 .
$$

This model provides a general framework to identify aggregate and sector-specific shocks which can be transmitted across sectors. While treating $\Pi_{0}(\vartheta)$ and $\Pi_{1}(\vartheta)$ as known given the values of $\vartheta$ and allowing the empirical factor-demand linkages $(\Gamma$ and $\Psi$ ) to determine the propagation mechanism for sector-specific shocks within the period (through $\Pi_{0}$ ) and across periods (through $\Pi_{1} \Pi_{0}^{-1}$ ), we estimate the remaining dynamic linkages, $\Phi$, from the data. Since this approach combines both empirical and theoretical identification strategies to identify the unknown parameters, we refer to it as a "hybrid approach".

\subsection{Structural Model Identification}

The "hybrid" approach to identification, as encapsulated in (13), makes use of the FSW structural growth model to identify $\Pi_{0}$ and $\Pi_{1}$ while allowing $\Phi$ to be unrestricted. An alternative approach is to use the structural growth model to identify $\Phi$ as well so the transmission mechanisms of the model in (8) are now fully governed by the empirical intermediate input-output linkages and capital flow linkages. Defining $\Phi_{F S W}$ as being identified by the structural model then setting $\Phi=\Phi_{F S W}$ in (8) yields the FSW model:

$$
\mathbf{y}_{t}=\Phi_{F S W} \mathbf{y}_{t-1}+\Pi_{0} S_{i} u_{t}+\Pi_{1} S_{i} u_{t-1}, \quad i=1,2 .
$$

\footnotetext{
${ }^{4}$ Some examples of factors that influence the dynamics linking sectors considered in the literature consist of demand complementarity and external economies of scale (Baxter and King 1991; Farmer and Guo 1994), interregional relationships (Caliendo et al. 2015), and aggregate demand spillovers (Murphy, et al 1989).

${ }^{5}$ To gauge to what extent the approximation may or may not bias the result, we set $\Phi=\Phi_{F S W}$, and recovered the factor vector $u_{t}$ with and without the approximation. The resulted correlation for each of the 17 factors before the Great Recession (i.e. the aggregate factor and the individual sectoral factor for each of the 16 sectors) and the 18 factors (i.e. the pre-crisis factors plus the GR factor) during the Great Recession range from 0.61 to 0.99 , with an average of 0.98 before the Great Recession and 0.86 during the recession. This result suggests that our approximation is reasonably good when tested within the FSW framework.
} 
A special case of (14) is the Horvath (1998) and Dupor (1999) model where capital is fully depreciated:

$$
\mathbf{y}_{t}=\left(I_{N}-\Gamma^{\prime}\right)^{-1} D_{\varphi} \mathbf{y}_{t-1}+\left(I_{N}-\Gamma^{\prime}\right)^{-1} S_{i} u_{t}, \quad i=1,2,
$$

where $D_{\varphi}$ is a $N$ dimensional diagonal matrix with the capital shares of each sector $\left(\varphi_{i}\right)$ on the diagonal. A further special case is the Long and Plosser (1983) model where there is no capital and intermediate inputs are assumed to be delivered with a one period lag:

$$
\mathbf{y}_{t}=\Gamma^{\prime} \mathbf{y}_{t-1}+S_{i} u_{t}, \quad i=1,2 .
$$

This model does not allow sectoral shocks to be transmitted contemporaneously across sectors, but through input-output linkages over time. As the reduced form models in (14)-(16) are derived from neoclassical multisector growth models, this class of models is referred to as the "structural approach".

\section{Empirical Analysis}

The dynamic factor specification based on the Hybrid model given in equation (13) is now applied to the U.S. sectoral data, covering the period 1947 to 2016. To maximize the available information, a mixed frequency strategy is adopted by combining both annual data (available from 1947 to 2016) and quarterly data (available from March 2005 onwards). The empirical properties of this model are then compared in Section 5 with the results based on the structural models in (14), (15), and (16).

\subsection{Estimation Issues}

The Hybrid model in (13) is estimated by maximum likelihood methods assuming that the structural disturbance vector $u_{t}$ in (4) is normally distributed. Let the full set of parameters be decomposed as:

$$
\theta_{0}=\{\Phi\}, \quad \theta_{1}=\left\{\lambda_{1}, \lambda_{2}, \cdots, \lambda_{16}, \sigma_{1}, \sigma_{2}, \cdots, \sigma_{16}\right\}, \quad \theta_{2}=\left\{\omega_{1}, \omega_{2,}, \cdots, \omega_{16}, \delta_{1}, \delta_{2}, \cdots, \delta_{16}\right\}
$$

where the vector $\theta_{0}$ contains the VAR autoregressive parameters in $\Phi, \theta_{1}$ contains the loadings on the aggregate and sectoral factors that operate in the pre-GR period, while $\theta_{2}$ contains the loadings on the GR factor that operates during the Great Recession, as well as the loadings on the sectoral factors to allow for structural breaks in these factors. 
Estimation of the hybrid model is performed in two stages. The first stage consists of obtaining consistent estimates of $\theta_{0}=\{\Phi\}$ by estimating the VAR in (13) subject to the restriction that the VAR parameter matrix is $\Phi+\Pi_{1} \Pi_{0}^{-1}$ with $\Pi_{1} \Pi_{0}^{-1}$ known. Defining the VAR disturbance in the first stage as $e_{t}=\Pi_{0} S_{i} u_{t}$, the second step involves choosing the set of loading parameters in the two regimes, $\theta_{1}$ and $\theta_{2}$, to maximize the joint normal log-likelihood corresponding to the pre-GR $\left(T_{1}\right)$ and GR periods $\left(T_{2}\right)$ :

$$
\ln L_{T}=\ln L_{1}\left(\theta_{0}, \theta_{1}\right)+\ln L_{2}\left(\theta_{0}, \theta_{1}, \theta_{2}\right)
$$

where the log-likelihoods of the two sub-periods are

$$
\ln L_{i}=-\frac{N}{2} \ln 2 \pi-\frac{1}{2} \ln \left|\Pi_{0} S_{i} S_{i}^{\prime} \Pi_{0}^{\prime}\right|-\frac{1}{2\left(T_{i}-1\right)} \sum_{t=2}^{T_{i}} e_{t}^{\prime}\left(\Pi_{0} S_{i} S_{i}^{\prime} \Pi_{0}^{\prime}\right)^{-1} e_{t}, \quad i=1,2
$$

with $S_{1}$ and $S_{2}$ defined in (7). Given the structure of the loadings in $S_{1}$ and $S_{2}$, combined with the cross-equation restrictions arising from the loadings on the common factor $a_{t}$ being the same over the total period, a gradient algorithm based on Newton-Raphson with numerical derivatives is used to compute the maximum likelihood estimates. Given the recursive structure of the log-likelihood, $\ln L_{1}\left(\theta_{0}, \theta_{1}\right)$ is initially maximized with respect to its parameters $\theta_{0}, \theta_{1}$, while consistent estimates of $\theta_{2}$ are obtained by maximizing $\ln L_{2}\left(\theta_{0}, \theta_{1}, \theta_{2}\right)$ with respect to $\theta_{2}$ given estimates of $\theta_{0}$ and $\theta_{1}$ from the previous step. To obtain asymptotically efficient estimates of $\theta_{2}$, the full log-likelihood in (17) is then maximized with respect to $\theta_{0}, \theta_{1}$ and $\theta_{2}$ jointly.

The initial choice of the sub-periods, $T_{1}$ and $T_{2}$, are respectively 1948 to 2006 in the case of the pre-GR period, and 2007Q1 to 2012Q2 for the Great Recession period. The sensitivity of the results to this choice of regime dates is examined later in Section $6 .{ }^{6}$

Whilst the parameters of the propagation channel linking sectors during the Great Recession are identified using all of the moments of the time series on the 16 sectors, greater precision is achieved by combining the annual and quarterly data given that quarterly data become available for this later period. To combine the mixed-frequency of annual and quarterly data, we adopt the following strategy. In the first step, the VAR parameters $(\Phi)$ are estimated based on the annual data covering the full sample period of 1947 to 2016. In the second step, the estimated VAR from the first step is used to extract the residuals for the two sub-periods corresponding to the annual and the year-on-year quarterly data by assuming that the dynamics embedded in the y-o-y quarterly data are well represented by the annual VAR. Formally, this is achieved by computing the residuals

\footnotetext{
${ }^{6}$ The period of the Great Recession is assumed to begin in 2007 to capture the early seeds of the crisis as is evidenced by the negative growth rates occurring in some sectors.
} 
in (13) over the crisis period with $\mathbf{y}_{t}$ replaced by the annualized quarterly growth rates, replacing $\Phi$ by its consistent estimator $\widehat{\Phi}$ in the first step, and treating the lag length of the VAR equal to one year. We use y-on-y growth rates to preserve the annual frequency of the data and hence the VAR parameter estimates. This assumption is valid provided that the dynamics of the annualized quarterly version of the model are largely captured by a single lag, as is specified in the annual VAR model. This assumption also has the advantage of circumventing degrees of freedom issues when trying to estimate a quarterly VAR separately just using crisis-period data.

\subsection{Preliminary Tests of the Model}

The Hybrid SVAR model in (13) is based on certain assumptions as regards its factor structure and its dynamic specification. Two preliminary tests of the model's structure are performed with the results and detailed explanations presented in the Appendix C.1.

The first performs the Bai-Ng (2002) information criteria tests to determine the optimal number of factors amongst the growth rates of the 16 sectors for the pre-GR period and the period of the Great Recession. The results provide strong evidence of a common factor with over $97 \%$ of aggregate volatility explained by the first principle component. The factor loadings on the first principal component for both sample periods suggests that it reflects an economy-wide factor with positive contributions from most sectors with roughly similar magnitudes. However, a comparison of the loadings across the two sub-periods reveals important differences suggesting changes in the factor structure during the Great Recession.

In estimating the 16-variate VAR in the first step the full set of annual data on sectoral growth rates covering the total sample period from 1948 to 2016 is used to estimate the parameters determining the model's dynamics $\Phi$. This strategy, although motivated by degrees of freedom issues from estimating a relatively large dimensional VAR given the size of the sample, implicitly assumes that the dynamics linking sectors does not significantly change during the period of the Great Recession relative to the pre-GR period. To assess the appropriateness of this assumption, we perform a multivariate version of the Diebold and Chen (1996) structural break test in which the timing of the crisis is treated as endogenous. As the distribution of the test statistic is non-standard, bootstrapped $p$-values are constructed by simulating the model under the null hypothesis of no structural break in the dynamics. The wild bootstrap of Davidson and Flachaire (2000) is adopted to capture the heteroskedasticity in the disturbance term arising from the presence of increases in

volatility during the period of the Great Recession. The empirical results find little evidence of structural breaks in the dynamics of most of the $N=16$ sectors over the sample period. 


\subsection{Factor Identification and Contributions to Aggregate Growth}

Table II shows the results of estimating the hybrid dynamic factor model in (13) by maximum likelihood methods. The autoregressive parameter estimates of the VAR are not reported here to save space. Most of the point estimates in Table II are statistically significant at the $5 \%$ level. The estimated loadings on the sector-specific shocks $\left(\hat{\sigma}_{i}, \hat{\omega}_{i}\right)$ are generally larger in absolute terms than the corresponding estimates on the underlying aggregate shocks $\left(\hat{\lambda}_{i}\right)$, suggesting that idiosyncratic shocks have a relatively larger impact on most sectors (especially for the Utilities, Construction and Health Care sectors).

An important feature of the empirical results in Table II is that the estimated loadings of the GR factor $\left(c_{t}\right)$ are relatively large and mostly statistically significant. This suggests that the additional common shock that emerges during the Great Recession plays a substantial role in driving sectoral and aggregate volatility during the Great Recession. While synchronizing most sectors' movements in the same direction, the GR factor drives Education, Health Care, Mining and Construction in the opposite direction. In addition, the size of the loadings implies that the GR factor has a particularly large impact on the Wholesale, Retail, Utility and Transportation sectors.

To understand the relative impact of the factors on the 16 sectors during the Great Recession, Table III presents the instantaneous decompositions of contributions to sectoral volatility from aggregate shocks, own sectoral shocks, shocks originated from other sectors and shocks from the GR factor. This table shows that the GR factor is again the dominating factor for most sectors with few exceptions: Mining which moves primarily with respect to aggregate shocks, and Construction, Education and Health Care which are mostly determined by their own sectoral shocks. The sectors most affected initially by the GR factor are the Durables, Nondurables and Transportation sectors. Unsurprisingly, the contributions of idiosyncratic sectoral shocks from the other sectors are in general relatively small on impact compared to the effects from own shocks. As these decompositions represent the instantaneous effects of all shocks, by construction these cross-sectoral effects are solely the result of I-O linkages and capital-flow linkages and thus suggest that these linkages are relatively small, at least contemporaneously.

A comparison of the loadings on the sector-specific factors in Table II across the two periods seems to suggest that for many of the sectors there is little change in sectoral volatility. A formal test of this change in the sectoral loadings across the two regimes given by a Wald test for each sector (see the last two columns of Table II) shows that only 5 of the 16 sectors show any statistically significant evidence of a change in sectoral volatility. A joint test of a structural break in all 16 sectoral loadings based on a likelihood ratio test is given in the bottom of the table. The value of the statistic is 127.41 , is nonetheless statistically significant at conventional levels, thereby providing 
strong support for the more general specification of the Hybrid model which allows for structural breaks in the sectoral factors.

Results in Table II suggest that the increase in volatility occurring during the Great Recession is primarily driven by the GR factor and less so at the disaggregate level. To gain further insight into the relative importance of the GR factor as well as the dynamics of the other factors identified by the model, we extract the factors from the estimated model by rearranging (13) and evaluating all parameters at their estimates as given in Table II. Formally the factors are computed according to:

$$
\widehat{u}_{t}=\left(\Pi_{0} \widehat{S}_{2}\right)^{-}\left(\mathbf{y}_{t}-\left(\widehat{\Phi}+\Pi_{1} \Pi_{0}^{-1}\right) \mathbf{y}_{t-1}\right)
$$

where $\widehat{u}_{t}=\left(\widehat{a}_{t}, \widehat{\eta}_{1 t}, \widehat{\eta}_{2 t}, \cdots, \widehat{\eta}_{16 t}, \widehat{c}_{t}\right)^{\prime}$ is the $(18 \times 1)$ vector at time $t$ containing the estimated economy-wide aggregate factor $\left(\widehat{a}_{t}\right)$, the 16 idiosyncratic factors $\left(\widehat{\eta}_{i t}\right)$ and the GR factor $\left(\widehat{c}_{t}\right)$, and $\left(\Pi_{0} \widehat{S}_{2}\right)^{-}$represents the generalized inverse of the estimated loading parameter matrix with $S_{2}$ defined in $(7) .^{7}$

Figure II(a) plots the time series of the estimated underlying aggregate factor $\left(\widehat{a}_{t}\right)$ and the estimated GR factor $\left(\widehat{c}_{t}\right)$ emerging during the crisis period. ${ }^{8}$ The large movements in the GR factor relative to the aggregate factor highlight the severity and timing of the Great Recession with the GR factor falling sharply in at the end of 2007 and reaching a trough in early 2009. Thereafter the GR factor continually increases over the next year before flattening from 2010 to 2012 providing support for the end of the Great Recessionary period. There is a large fall in the aggregate factor with a relatively smaller fall in the GR factor at the end of 2011 to early 2012, coinciding with the European debt crisis.

To identify how these factors, together with the sectoral factors, impact upon aggregate output, we substitute the factors obtained from (19) back into the estimated model one-by-one to identify their individual contributions on the aggregate growth rate in output. Specifically, at each point in time the impact of a shock on the sectoral growth rates are combined to generate an aggregate growth rate. The respective contributions of the aggregate factor, the joint sectoral factors and the GR factor are constructed respectively as:

$$
\begin{aligned}
& y_{a, t}=\left[\left(I_{N}-\left(\widehat{\Phi}+\Pi_{1} \Pi_{0}^{-1}\right) L\right)^{-1} \Pi_{0} \widehat{S}_{2}^{\lambda} \widehat{u}_{t}\right]^{\prime} w \\
& y_{\eta, t}=\left[\left(I_{N}-\left(\widehat{\Phi}+\Pi_{1} \Pi_{0}^{-1}\right) L\right)^{-1} \Pi_{0} \widehat{S}_{2}^{\omega} \widehat{u}_{t}\right]^{\prime} w \\
& y_{c, t}=\left[\left(I_{N}-\left(\widehat{\Phi}+\Pi_{1} \Pi_{0}^{-1}\right) L\right)^{-1} \Pi_{0} \widehat{S}_{2}^{\delta} \widehat{u}_{t}\right]^{\prime} w
\end{aligned}
$$

\footnotetext{
${ }^{7}$ The first observation of the estimated factors $\widehat{u}_{1}$, is calculated by setting $\mathbf{y}_{0}$ to the sample mean of the annual data from 2007 to 2012.

${ }^{8}$ For the purpose of presentation clarity, confidence intervals are not reported in the following three figures, but available upon request.
} 
where $w=\left(w_{1}, w_{2}, \cdots, w_{N}\right)^{\prime}$ is a $(N \times 1)$ vector containing the average weights of each sector in aggregate output during the Great Recession. The contemporaneous shocks matrix $\widehat{S}_{2}^{k}, k=$ $\{\lambda, \omega, \delta\}$, is the estimated loading parameter matrix where $k$ identifies the parameter vector that is

not constrained to zero. For example, $\widehat{S}_{2}^{\lambda}$ indicates that the loading parameters on $a_{t}$ are set equal to their maximum likelihood estimates while restricting $\sigma_{i}=\delta_{i}=0, \forall i$. By construction replacing $\widehat{S}_{2}^{k}$ by $\widehat{S}_{2}$ perfectly recovers aggregate output.

Figure II(b) presents the contribution decomposition based on (20)-(22). The large initial fall in the GR factor identified in Panel A is translated into a substantial drop in aggregate output growth of nearly $10 \%$ per annum. The sectoral and aggregate factors also contribute to reductions in aggregate output, especially in 2009, but these are of a smaller order of magnitude compared to the contributions from the GR factor at the onset of the crisis. By the end of 2009 the contributions of the aggregate, sectoral and GR factors to the negative aggregate growth are roughly similar.

An alternative way to understand the relative importance of the GR factor in contributing to the Great Recession is to run a counterfactual experiment which simulates the estimated model without the presence of the GR factor. The results of this experiment are contained in Figure III which gives the actual growth rates of output during the recession together with the implied growth rate if the GR factor was absent. At the height of the Recession in mid-2009 where the fall in the aggregate output growth is at around $-12 \%$ per annum, the model predicts that this fall would have been halved if the GR factor was not present.

\subsection{Dynamic Cross-Sector Spillovers}

To gain further perspective on the relative strength of the interactions amongst U.S. sectors, especially the ones that tend to take place over time, we examine the Diebold and Yilmaz (2009) spillover decompositions for the pre-GR and GR periods. This requires decomposing the forecast error variances of the sectoral growth rates into the separate contributions from the structural factors of the hybrid model in (13). We present the result at the end of a 3-year period because the variance decompositions tends to stabilize after 3 years for most sectors.

The construction of the spillover index involves two steps. First, the orthogonalized impulse responses for the first three periods are computed as $R_{0}=\Pi_{0} S_{i}, R_{1}=\left(\Phi+\Pi_{1} \Pi_{0}^{-1}\right) \Pi_{0} S_{i}$ and $R_{2}=\left(\Phi+\Pi_{1} \Pi_{0}^{-1}\right)\left(\Phi+\Pi_{1} \Pi_{0}^{-1}\right) \Pi_{0} S_{i}$, with all parameters evaluated at their maximum likelihood estimates, where $R_{h}, h=0,1,2$, is a $(16 \times 17)$ matrix in the pre-GR period and a $(16 \times 18)$ matrix during the period of the Great Recession, which contains the impulse responses of the effect of factor $j$ on sector $i$ in period $h$, with typical element $r_{h, i, j}$. Second, since the structural factors are independent, we construct the 3 -year spillover index from the variance error decomposition 
obtained from the squared elements of the impulse responses.

Table IV presents the 3-year-ahead forecast error variance decompositions of the 16 sectors during the pre-GR period as well as the period of the Great Recession. The decompositions are presented in terms of the aggregate factor, the combined contributions of the external sectorspecific factors, and the contribution of the GR factor in the recession period. ${ }^{9}$ Table IV shows the percentage contributions of different factors to the volatility of each row sector (under the header "From") and the overall contribution to the volatility of the other sectors by each row sector (under the header "To"). The contributions of the sectoral factors in Column (2) and (6) are the combined contributions from external sector-specific shocks An important feature of the results is that the effects of external sector-specific shocks dominate the effects of aggregate shocks on sectoral volatility before the crisis for the majority sectors, pointing to the important role of sector-specific shocks. The Diebold-Yilmaz spillover index during the pre-GR period is 51\%, suggesting that the majority of sectoral volatility comes from external factors, which are dominated by external sectoral shocks (28\%), followed by aggregate shocks (23\%). During the Great Recession the contribution of the GR factor dominates the aggregate factor and the external sectoral factors for most sectors, with the exceptions being Construction, Education and Health Care sectors which are largely driven by external sectoral shocks. The importance of the GR factor is highlighted by the increase in the Diebold-Yilmaz spillover index from 51\% prior to the crisis period to nearly $76 \%$ in the Great Recession, with the GR factor contributing to $48 \%$.

Table IV also presents the overall contribution to the volatility of other sectors by each row sector (under the header "To"). Of the 16 sectors, Finance and Nondurables Manufacturing have the greatest impact on all other sectors.

\subsection{Dynamic Spillover Effects of the Finance and Insurance Sector}

To identify the dynamic roles of shocks originating in different sectors, we track the spillover effects of all sectors over time by computing a term-structure type of graph of the Diebold-Yilmaz spillover index. Figure VI presents such a plot of the cross-sectoral contributions to the spillover index for selected sectors with the forecast horizon running from 1 year to 7 years during the recession. The sectors reported are the top six sectors which appear to have the largest medium-and-long-term spillover effects on the other sectors: Finance, Nondurable, Wholesale, Construction, Durables and Information.

The striking result of Figure VI is the importance of the cross-sectoral linkages between the

\footnotetext{
${ }^{9}$ More detailed decompositions showing the complete cross-sector spillover matrix - the individual contributions of sector-specific shock in $i$ to the forecast error variance in sector $j$ - are provided in Tables A.4 and A.5 in Appendix $\mathrm{C}$, for the pre-GR and crisis periods respectively.
} 
Finance sector and other sectors. The impact of Finance on the rest of the economy dominates that of any other sector. Its contribution to the overall spillover index was initially around 10\%, which is mostly dictated by its input-output linkages with other sectors, but rises quickly to over $30 \%$ after a year through its dynamic spillover effects, and over $45 \%$ after 5 years. The Nontradables manufacturing sector is also found to be relatively important, especially for the first two years.

\section{Model Comparisons}

An important empirical result stemming from the work of FSW is that it is aggregate shocks that dominate sectoral shocks as the main determinant of aggregate volatility. Given the empirical results of the Hybrid model presented so far, it is of interest to see if these empirical findings also translate to the broader economy containing both manufacturing and non-manufacturing sectors, as well as to a period of greater volatility as characterized by the Great Recession.

Table V compares the performance of the Hybrid model in (13) with the structural models of FSW in (14), Dupor-Horvath in (15) and Long-Plosser in (16). The results are presented for the period of the Great Recession as well as the pre-GR period, which is comparable to the period investigated by FSW. ${ }^{10}$ All models are estimated by maximum likelihood methods. ${ }^{11}$ During the Great Recession, Table V reveals that the Hybrid model specification performs well in capturing the magnitude of the increase in volatility, although this model slightly underestimates aggregate volatility compared to the three structural models which over-estimate aggregate volatility.

The Hybrid model captures the interdependence amongst sectors during both sample periods, with average correlations of 0.27 (pre-GR period) and 0.44 (GR period), compared to 0.26 and 0.45 respectively for the data. The FSW and Long-Plosser structural models also capture the observed increase in interdependence amongst sectors, although these models over-predict the strength of this interdependence in both sub-periods with average correlations in excess of the average correlations from the data. In contrast, the Dupor-Horvath structural model does not even capture the observed increase interdependence amongst sectors. A comparison of the RMSE statistics presented in Table V further demonstrates the superior performance of the Hybrid model as it yields the lowest RMSE of $23 \%$ during the Great Recession, whereas the RMSEs of the structural models range between $26 \%$ and $32 \%$. The same qualitative result is also true for the pre-GR period. The ability of the Hybrid

\footnotetext{
${ }^{10} \mathrm{FSW}$ in their empirical analysis also take into account the effects of the "Great Moderation" period where there is a fall in the volatility of real output. This feature of the data during the pre-GR period is also considered in discussing the robustness properties of the Hybrid model in Section 6

${ }^{11} \mathrm{~A}$ similar two-step approach as used to estimate the parameters of the Hybrid model, is adopted for the FSW, Dupor-Horvath and Long-Plosser models in equations (14), (15) and (16) respectively. The only difference however, is that in the first step as there is no need to estimate any parameters the residuals of the structural models that are needed in the second stage of the maximum likelihood procedure are simply "filtered".
} 
model to capture the interdependencies amongst sectors is demonstrated graphically in Figure IV which shows scatter plots of estimated pair-wise correlations between sectoral growth generated by all four models versus the correlations in the data. Inspection of the figure shows substantially higher heterogeneity amongst sectors manifested by large negative correlations between certain sector-pairs, which are captured by the Hybrid model, but not by the three structural models.

Decomposing aggregate volatility during the GR period in terms of the three factors, Table V shows that the Hybrid model assigns a higher contribution of $14 \%$ to sectoral shocks compared to the three structural models where the contributions of sectoral shocks are at most $6 \%$. Comparing the contribution from the aggregate, sectoral and GR factors, the GR factor is found to be the dominant factor in the Hybrid model yielding a contribution estimate of 75\%. The FSW and LongPlosser models also assign an important contribution to the GR factor, albeit smaller than it is for the Hybrid model, with respective contributions of $66 \%$ and $36 \%$. For the Dupor-Horvath model the contribution of the GR factor is just 5\%. The difference in the contribution decompositions between the Hybrid model and the three structural models is starker before the Great Recession with all three structural models finding that aggregate shocks dominate the sector-specific shocks, whereas the Hybrid model attributes contribute $60 \%$ of aggregate volatility to idiosyncratic sectoral shocks. These results are by and large mirrored by the spillover index estimates given in Table V.

These comparisons all tend to point to one conclusion: although material input-output relationships - which have been the center of the existing literature of multi-sector growth — play a meaningful role of transmitting shocks across sectors, there are other significant potential sources of intersectoral linkages in action. More importantly, viewing only through the lens of input-output and capital flow linkages may underestimate the contribution of sector-specific shocks in generating aggregate variability because spillovers generated by these models are much more limited. This can be demonstrated further by comparing the spillover matrices generated by the Hybrid approach and the three structural based approaches.

Figure V depicts the estimated kernel density distribution of the elements of the spillover matrices for all four models. All four models generate highly skewed distributions of the sector-pairwise spillovers, suggesting that a small number of sectors do play a key role in disseminating shocks, a result which is consistent with previous findings in the literature (such as Carvalho, 2007; Acemoglu et al. 2012). More importantly, the distributions of the structural models based on the FSW, Dupor-Horvath and Long-Plosser economies have thinner tails implying that I-O linkages point to an even smaller set of sectors which have significant spillover impacts. 


\section{Robustness Checks}

This section summarizes the results from performing a number of checks to examine the robustness of the previous empirical results obtained from the Hybrid SVAR model. We begin by examining the sensitivity to changes in input-output linkages over time, and then turn to augmenting the Hybrid model to correct for the Great Moderation period starting in the mid-1980s. The results from reestimating the model for alternative starting dates of the Great Recession period are presented next. Lastly, we perform a "placebo test" to investigate whether the additional common factor playing an important role is a unique feature for the Great Recession when compared to other crisis periods. All details of the results are presented in Appendix C.3.

Changes in the Input-Output Matrix The empirical analysis so far assumes constant inputoutput linkages across sectors over time. The U.S. I-O tables are updated every five years to take into account changes in intersectoral linkages in the production of intermediate goods. Whilst changes in I-O tables in general tend to be slowly evolving over time, it is possible that the nature of the shocks underlying the large changes in sectoral output during the Great Recession may have resulted in more dramatic changes in the input-output relationships connecting sectors. For example, a negative shock generating a disproportionately large impact on the financial sector might potentially also reduce the relative importance of this sector as an input supplier to other sectors. To address this concern the model is re-estimated by replacing the 2002 IO matrix by the 2009 IO tables for the period of the Great Recession while still using the 2002 tables for the pre-GR period. Qualitatively the parameter estimates of the revised estimated model (reported in Table A.6) in general do not change from the estimates reported in Table II based solely on 2002 IO tables. The revised model also generates similar summary statistics as regards aggregate output volatility, sectoral correlations and the Diebold-Yilmaz spillover index (see Table A.7).

Great-Moderation It has been well-documented that aggregate growth volatility fell by roughly half starting in the mid-1980s associated with the Great Moderation, suggesting that there might be structural changes in the period prior to the Great Recession. In addition, when applying a structural factor model to U.S. quarterly manufacturing data, FSW document a significant shift in the relative importance of sectoral shocks compared to aggregate shocks in driving the variation in industrial production after the Great Moderation. As our analysis uses data encompassing the Great Moderation period, it is of interest to identify whether the presence of the Great Moderation impacts upon the existing set of empirical results.

To determine the sensitivity of the empirical results to the presence of the Great Moderation we 
adopt the following two experiments. The first involves reestimating the factor loadings by starting the pre-GR period in 1984. In the second experiment the full sample period is used, but a 3-regime model is now estimated with the pre-GR period decomposed into pre- and post-moderation periods through the inclusion of a structural break parameter to capture changes in volatility during the Great Moderation period. For both experiments the empirical results presented in Table V do not change qualitatively, with sectoral shocks still playing a similar role in driving the pre-GR aggregate fluctuations during the period of the Great Moderation. The decomposition of shocks during the period of the Great Recession also does not change significantly, with the GR factor still having the greatest contribution to aggregate volatility of over $75 \%$, compared to sectoral shocks which contribute nearly $20 \%$, while the aggregate shock has the smallest contribution of less than $5 \%$ (see Table A.8). ${ }^{12}$ In general, these results suggest that by extending the factor structure to allow for the period of the Great Moderation that occurred prior to the Great Recession, does not significantly alter our existing findings as regards to the relative importance of the factors in determining aggregate output volatility.

Dating the Onset of the Great Recession Our initial choice of the starting date of the Great Recession is the first quarter of 2007, which is adopted to capture the early seeds of the 20072008 financial crisis. To determine the sensitivity of the estimated factor loadings to this choice of starting date, the model is re-estimated for alternative starting dates ranging from the first quarter of 2007 to the second quarter of 2008. Using information criteria based on the HIC and SIC statistics, the optimal starting date is found to be the first quarter of 2008. More importantly, by reestimating the model for each of the 6 alternative starting dates of the crisis, the factor loadings were nonetheless found to be robust to these alternative choices of starting dates (see Figure A.2).

How Special is the Great Recession? As shown in Figure A.3, the average cross-sectoral correlations of output growth — calculated based on a six-year rolling window from 1950 to 2005tend to rise during some of previous recessions as well, indicating that recessions are generally a time of heightened co-movement across sectors. This observation raises the question that whether the dominant role of the GR factor in aggregate volatility during the Great Recession is just an artifact of including a second common factor during the Great Recession while allowing for only one common factor during the rest of the sample period. To address this concern, we perform the

\footnotetext{
${ }^{12}$ As shown by this exercise, splitting the pre-GR period into pre-Great Moderation and Great Moderation subperiods does not change the dominant role of sector-specific shocks in our analysis. This finding is different from FSW, where they find an increase in the relative role of sectoral shocks over aggregate shocks from approximately $20 \%$ to $50 \%$ in determining the variation in industrial production since the start of the Great Moderation period in 1984. The stark differences between our study and previous work are that (i) we include all private sectors in the analysis while they focus on industrial production sectors, (ii) we do not restrict the dynamic spillovers to the I-O linkages.
} 
following "placebo" test. ${ }^{13}$ The strategy is to specify the factor structure whereby an additional common factor in the model now occurs over every six years on a rolling basis. In order to compare the Great Recession with previous crises, we use annual data throughout the entire sample for this exercise. Figure A.3 then reports the share contribution of this additional common factor to total volatility against the middle year of the rolling window. The shaded area indicates the recessions (from peak to trough of a business cycle) using the NBER database of U.S. business cycle expansions and contractions.

Our analysis shows that the contribution of the additional crisis factor to total volatility is low in previous recessions and much lower compared to its contribution during the Great Recession. For example, in the previous two relatively long recessions of 1973-1978 and 1979- 1984, its contributions averaged about $6 \%$ and $21 \%$ respectively. Similar qualitative results are observed for other recessions except for the 1957-1958 recession where the contribution of the second common factor spiked but only at a lower level than the contribution of the GR factor of $75 \%$ reported for the hybrid model during the Great Recession period. Some recessions, such as 1979-1984, 1990-1991 and 2001 recessions, observed some increase in the contribution of the second common factor with a significant lag of 2-4 years. However, again these contributions are much less than the contribution of the GR factor. In fact the Great Recession is the only crisis period which experienced dramatic increases in both the cross-correlations (of almost $60 \%$ on average) and the contribution from the second common factor reaching a maximum of over $70 \% .{ }^{14}$ This empirical result not only demonstrates the important role of the GR factor in explaining the increases in volatility observed during the Great Recession, but also highlights the uniqueness of this event when compared with previous crisis periods.

\section{Conclusions}

In this paper, we examine the importance of sectoral shocks and the associated mechanisms that channel shocks to the rest of the economy, especially during the Great Recession. In contrast with existing studies of industrial sectors, we find that sector-specific shocks play a significant role in explaining changes to aggregate output before the recession, contributing to more than half of aggregate variability. However, the Great Recession is characterized by the rise of an additional

\footnotetext{
${ }^{13}$ We thank a referee for suggesting this robustness test.

${ }^{14}$ Ideally, one would want to include multiple regimes in the general model to allow for the possibility of a second common factor in other recessions. But given that many of the past recessions in the U.S. prior to the Great Recession are relatively short with durations of around 2 years and that only annual data are available for the sectors investigated in the paper for these periods, a shortage of degrees of freedom prohibits estimation of such a model. To circumvent these computational issues, our current strategy adopted is to include a set of dummy variables for the previous crises as explained in footnote 2 .
} 
common shock. This additional common shock contributes significantly to the rise in aggregate variability during the crisis, accounting for around $3 / 4$ of total volatility. In addition, shocks originating in the Finance and Insurance sector are found to have the largest spillover effects to the rest of the economy than other sectors.

Even though intersectoral linkages are essential to sectoral comovement and aggregate volatility, we find that the observed measure of factor demand linkages falls short in explaining the observed amount of spillovers across sectors, suggesting other important sources of linkages might be missing. Therefore, when applied to U.S. nonfarm business sector data, the structural models (i.e. FSW, Dupor-Horvath and Long-Plosser) do not perform as well as the hybrid model which allows for more flexible dynamic transmission of idiosyncratic sectoral shocks. 


\section{References}

[1] Acemoglu Daron, Vasco M. Carvalho, Asuman Ozdaglarx and Alireza Tahbaz-Salehi, "The Network Origins of Aggregate Fluctuations," Econometrica 80 (2013), 1977-2016.

[2] Acemoglu Daron, Asuman Ozdaglarx and Alireza Tahbaz-Salehi, "The Network Origins of Large Economic Downturns," NBER Working Paper 19230 (2013).

[3] Ando, Sakai, "Measuring US sectoral shocks in the world input-output network", Economics Letters 125(2014), 204-207.

[4] Atalay, Enghin, "How Important Are Sectoral Shocks?," American Economic Journal: Macroeconomics, 9(2017), 254-280.

[5] Baxter, Marianne and Robert G. King, "Productive Externalities and Business Cycles," Federal Reserve Bank of Minneapolis, Institute for Empirical Macroeconomics Discussion Paper 53 (1991).

[6] Boldrin, Michele, Carlos Garriga, Adrian Peralta-Alva and Juan Sanchez, "Reconstructing the Great Recession," Federal Reserve Bank of St. Louis Working paper 2013-006B (2013).

[7] Brunnermeier, Markus K. and Yuliy Sannikov, "A Macroeconomic Model with a Financial Sector," American Economic Review 104 (2013), 379-421.

[8] Caliendo, Lorenzo, Fernando Parro, Esteban Rossi-Hansberg, Pierre-Daniel Sarte, "The Impact of Regional and Sectoral Productivity Changes on the U.S. Economy," NBER Working Paper No. 20168 (2014).

[9] Carvalho, Vasco M. and Xavier Gabaix, "The Great Diversification and its Undoing," American Economic Review 103 (2013), 1697-1727.

[10] Carvalho, Vasco M., "From Micro to Macro via Production Networks," Journal of Economic Perspectives 28 (2014), 23-48.

[11] Craine, Roger and Vance L. Martin, "International Monetary Policy Surprise Spillovers," Journal of International Economics 75 (2008), 180-196.

[12] Di Giovanni, Julian , Andrei Levchenko and Isabelle Mejean, "Firms, Destinations, and Aggregate Fluctuations," Econometrica 82 (2014), 1303-1340.

[13] Diebold, Francis X. and Yilmaz, Kamil, "Measuring Financial Asset Return and Volatility Spillovers, with Application to Global Equity Markets," The Economic Journal 119 (2009), 158-171.

[14] Dungey, Mardi, Renée Fry, Brenda González-Hermosillo and Vance L. Martin, "Empirical Modelling of Contagion: A Review of Methodologies," Quantitative Finance 5 (2005), 9-24.

[15] Dungey, Mardi, Renée Fry, Brenda González-Hermosillo and Vance L. Martin, Transmission of Financial Crises and Contagion: A Latent Factor Approach. Oxford University Press, Oxford (2010).

[16] Dupor, William, "Aggregation and Irrelevance in Multi-Sector Models," Journal of Monetary Economics 43 (1999), 391-409. 
[17] Farmer, Rae and Jang-Ting Guo, "Real Business Cycles and the Animal Spirits Hypothesis," Journal of Economic Theory 63 (1994), 42-72.

[18] Foerster, Andrew T., Pierre-Daniel G. Sarte and Mark W. Watson, "Sectoral Versus Aggregate Shocks: A Structural Factor Analysis of Industrial Production," Journal of Political Economy 119 (2011), 1-38.

[19] Forni, Mario, and Lucrezia Reichlin, "Let's Get Real: A Dynamic Factor Analytical Approach to Disaggregated Business Cycle Dynamics," Review of Economic Studies 65 (1998), 453-474.

[20] Gabaix, Xavier, "The Granular Origins of Aggregate Fluctuations," Econometrica 79 (2011), 733-772.

[21] Horvath, Michael, "Cyclicality and Sectoral Linkages: Aggregate Fluctuations From Sectoral Shocks," Review of Economic Dynamics 1 (1998), 781-808.

[22] Lucas, Robert, "Understanding Business Cycles," Carnegie-Rochester Conference Series on Public Policy 5(1): 7-29.

[23] Liu, Zheng, Pengfei Wang and Tao Zha, "Land-Price Dynamics and Macroeconomic Fluctuations," Econometrica 81 (2013), 1147-1184.

[24] Long, John B., and Charles I. Plosser, "Real Business Cycles," Journal of Political Economy 91 (1983), 39-69.

[25] Murphy, Kevin M., Andrei Shleifer and Robert W. Vishny, "Building Blocks of Market Clearing Business Cycle Models," in NBER Macroeconomics Annual (1989), edited by Olivier Blanchard and Stanley Fischer, 247-301.

[26] Rigobon, Roberto and Brian Sack, "Measuring the Reaction of Monetary Policy to the Stock Market," Quarterly Journal of Economics 118 (2003), 639-669.

[27] Rigobon, Roberto and Brian Sack, "The Impact of Monetary Policy on Asset Prices," Journal of Monetary Economics 51 (2004), 1553-1575.

[28] Shea, John, "Complementarities and Comovements," Journal of Money, Credit and Banking 34 (2002), 412-433. 
Table I: Summary statistics on U.S. sectoral output growth: based on annual data

\begin{tabular}{|c|c|c|c|c|c|c|c|}
\hline \multirow[t]{2}{*}{ Industry } & \multicolumn{2}{|c|}{$\begin{array}{c}\text { Total Period } \\
(1948-2016)\end{array}$} & \multicolumn{2}{|c|}{$\begin{array}{c}\text { Pre-GR } \\
(1948-2006)\end{array}$} & \multicolumn{2}{|c|}{$\begin{array}{c}\text { GR } \\
(2007-2012)\end{array}$} & \multirow{2}{*}{$\begin{array}{c}\text { Average } \\
\text { Share } \\
\left(w_{i}\right)\end{array}$} \\
\hline & Mean & SD & Mean & SD & Mean & SD & \\
\hline Mining & 1.11 & 4.91 & 1.13 & 4.25 & 2.63 & 4.19 & $2.17 \%$ \\
\hline Utilities & 2.09 & 6.11 & 2.59 & 5.89 & -2.29 & 7.27 & $2.13 \%$ \\
\hline Construction & 2.18 & 6.24 & 2.82 & 5.92 & -5.85 & 4.88 & $6.15 \%$ \\
\hline Durables Manufacturing & 2.80 & 6.35 & 3.20 & 5.91 & -0.48 & 9.46 & $18.09 \%$ \\
\hline Nondurables Manufacturing & 1.96 & 3.18 & 2.27 & 3.08 & -0.90 & 3.19 & $16.39 \%$ \\
\hline Wholesale Trade & 4.38 & 5.58 & 5.05 & 4.58 & 0.24 & 10.01 & $5.30 \%$ \\
\hline Retail Trade & 2.77 & 4.09 & 3.04 & 4.09 & 0.15 & 4.12 & $6.98 \%$ \\
\hline Transportation & 2.45 & 4.41 & 2.72 & 4.33 & 0.00 & 5.14 & $4.25 \%$ \\
\hline Information & 4.65 & 2.46 & 4.91 & 2.42 & 2.57 & 2.37 & $4.39 \%$ \\
\hline Finance and Insurance & 4.21 & 3.71 & 4.90 & 3.44 & -0.90 & 2.48 & $5.97 \%$ \\
\hline Real Estate and Rental & 3.68 & 1.97 & 4.09 & 1.60 & 0.21 & 2.12 & $9.31 \%$ \\
\hline Professional and Business & 4.59 & 2.98 & 4.94 & 2.84 & 2.05 & 3.34 & $7.32 \%$ \\
\hline Education Services & 3.81 & 2.56 & 4.07 & 2.57 & 3.16 & 1.80 & $0.77 \%$ \\
\hline Health Care and Social & 4.26 & 2.01 & 4.49 & 2.02 & 2.44 & 0.48 & $4.47 \%$ \\
\hline Recreation and Entertainment & 2.68 & 2.59 & 2.85 & 2.52 & 0.48 & 2.63 & $3.77 \%$ \\
\hline Other Services & 2.49 & 3.01 & 2.81 & 2.85 & -0.79 & 2.90 & $2.54 \%$ \\
\hline
\end{tabular}


Table II: Parameter estimates of the dynamic factor model of sectoral real output growth, based on the Hybrid model specification

\begin{tabular}{|c|c|c|c|c|c|c|c|c|c|c|}
\hline \multirow[t]{3}{*}{ Industry } & \multirow{2}{*}{\multicolumn{2}{|c|}{ Loadings on $a_{t}$}} & \multirow{2}{*}{\multicolumn{4}{|c|}{\begin{tabular}{l}
\multicolumn{2}{c}{ Loadings on $\eta_{t}$} \\
Pre-GR
\end{tabular}}} & \multirow{2}{*}{\multicolumn{2}{|c|}{ Loadings on $c_{t}$}} & \multirow{2}{*}{\multicolumn{2}{|c|}{$\begin{array}{l}\text { Structural } \\
\text { Break Test }\end{array}$}} \\
\hline & & & & Pre-GR & & & & & & \\
\hline & $\widehat{\lambda}_{i}$ & s.e. & $\widehat{\sigma}_{i}$ & s.e. & $\widehat{\omega}_{i}$ & s.e. & $\widehat{\delta}_{i}$ & s.e. & Stat. & p-value \\
\hline Mining & $2.37^{*}$ & $(0.25)$ & $2.47^{*}$ & $(0.23)$ & $2.03^{*}$ & $(0.27)$ & -0.56 & $(0.49)$ & -0.43 & 0.21 \\
\hline Utilities & -0.39 & $(0.54)$ & $4.56^{*}$ & $(0.36)$ & $5.56^{*}$ & $(0.46)$ & $2.99 *$ & $(0.71)$ & 1.01 & 0.09 \\
\hline Construction & $0.66^{*}$ & $(0.27)$ & $2.45^{*}$ & $(0.2)$ & $2.66^{*}$ & $(0.24)$ & $-0.92^{*}$ & $(0.36)$ & 0.22 & 0.49 \\
\hline Durables & $0.96^{*}$ & $(0.24)$ & $1.30^{*}$ & $(0.12)$ & $1.08^{*}$ & $(0.13)$ & $2.69^{*}$ & $(0.3)$ & -0.22 & 0.21 \\
\hline Nondurables & $-0.57^{*}$ & $(0.15)$ & $1.28^{*}$ & $(0.1)$ & $1.17^{*}$ & $(0.13)$ & $1.07^{*}$ & & -0.11 & 0.53 \\
\hline Wholesale & $2.95^{*}$ & $(0.5$ & $2.61^{*}$ & $(0.29)$ & $4.61^{*}$ & $(0.42)$ & $5.56^{*}$ & $(0.8$ & 2.00 & 0.00 \\
\hline Retail & $1.68^{*}$ & $(0.33)$ & $2.40^{*}$ & $(0.23)$ & $1.72^{*}$ & $(0.18)$ & $3.38^{*}$ & $(0.44)$ & -0.68 & 0.02 \\
\hline Transportation & $0.94^{*}$ & $(0.28)$ & $2.19^{*}$ & $(0.18)$ & $1.79^{*}$ & $(0.17)$ & $2.93^{*}$ & $(0.35)$ & -0.39 & 0.11 \\
\hline Inforn & $0.44^{*}$ & $(0.15)$ & $1.29^{*}$ & $(0.10)$ & $1.24^{*}$ & $(0.1)$ & $0.96^{*}$ & $(0.1$ & -0.05 & 0.75 \\
\hline Finance & $-1.42^{*}$ & $(0.24)$ & $1.90^{*}$ & $(0.17)$ & $2.06^{*}$ & $(0.24)$ & $1.65^{*}$ & $(0.39)$ & 0.16 & 0.58 \\
\hline Real Estate & $0.68^{*}$ & $(0.13)$ & $1.18^{*}$ & $(0.10)$ & $1.14^{*}$ & $(0.1)$ & $0.95^{*}$ & $(0.20)$ & -0.03 & 0.82 \\
\hline Professional & $0.29 *$ & $(0.07)$ & $1.10^{*}$ & $(0.09)$ & $0.64^{*}$ & $(0.05)$ & $0.35^{*}$ & $(0.09)$ & -0.46 & 0.00 \\
\hline Education & $-0.42^{*}$ & $(0.17)$ & $1.54^{*}$ & $(0.12)$ & $1.66^{*}$ & $(0.13)$ & $-0.85^{*}$ & $(0.22)$ & 0.12 & 0.52 \\
\hline Health & 0.07 & $(0.08)$ & $1.51^{*}$ & $(0.12)$ & $0.51^{*}$ & $(0.05)$ & $-0.76^{*}$ & $(0.09)$ & -1.00 & 0.00 \\
\hline Recreation & $0.71^{*}$ & $(0.15)$ & $1.54^{*}$ & $(0.13)$ & $0.94^{*}$ & $(0.09)$ & $1.35^{*}$ & $(0.20)$ & -0.60 & 0.00 \\
\hline \multirow[t]{2}{*}{ Other Services } & $0.92^{*}$ & $(0.16)$ & $1.89^{*}$ & $(0.16)$ & $1.50^{*}$ & $(0.14)$ & 0.16 & $(0.25)$ & -0.39 & 0.07 \\
\hline & & & & & & & & Joint: & 127.41 & 0.00 \\
\hline
\end{tabular}

Notes: QMLE standard errors are in the brackets. * indicates significance at the $5 \%$ level. Individual structural break test based on a Wald statistic, while the joint test is based on a likelihood ratio statistic with 16 degrees of freedom. 
Table III: Instantaneous decomposition of sectoral volatility based on the Hybrid model during the Great Recession

\begin{tabular}{lrrrc}
\hline \hline Industry & Aggregate & \multicolumn{2}{c}{ Sectoral } & GR \\
\cline { 3 - 4 } & & Own & Other & \\
\hline Mining & 60.18 & 37.60 & 1.00 & 1.22 \\
Utilities & 0.20 & 69.18 & 0.53 & 30.09 \\
Construction & 17.12 & 68.51 & 2.87 & 11.49 \\
Durables & 11.93 & 6.41 & 2.05 & 79.61 \\
Nondurables & 0.39 & 18.90 & 3.76 & 76.95 \\
Wholesale & 14.32 & 26.00 & 0.27 & 59.41 \\
Retail & 15.64 & 11.55 & 0.72 & 72.09 \\
Transportation & 7.36 & 14.20 & 0.82 & 77.63 \\
Information & 9.44 & 23.34 & 1.83 & 65.39 \\
Finance & 14.63 & 43.11 & 0.24 & 42.01 \\
Real Estate & 12.78 & 33.90 & 2.68 & 50.64 \\
Professional & 14.12 & 8.66 & 4.87 & 72.35 \\
Education & 3.58 & 90.18 & 4.58 & 1.66 \\
Health Care & 2.48 & 68.14 & 15.25 & 14.13 \\
Recreation & 12.07 & 12.21 & 1.96 & 73.76 \\
Other Services & 23.22 & 42.41 & 2.82 & 31.55 \\
\hline \hline
\end{tabular}

Notes: Sectoral volatilities are calculated as the diagonal components of $\Pi_{0} S_{2} S_{2}^{\prime} \Pi_{0}^{\prime}$. 
Table IV: Diebold-Yilmaz spillover decompositions, based on a three-year forecast horizon using the hybrid model

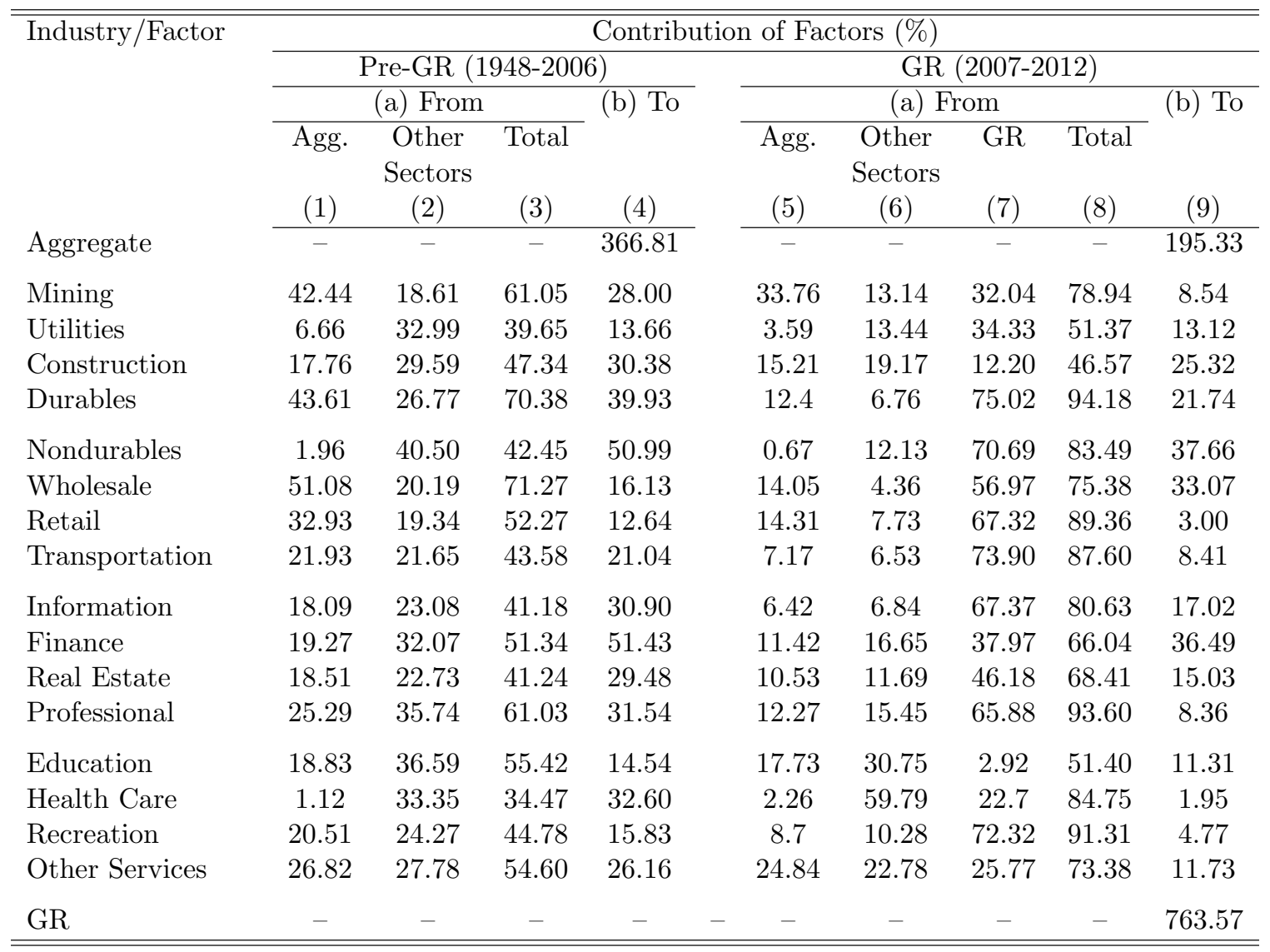

Notes: This table shows (a) the percentage contribution to volatility of each row sector $(i)$ by the aggregate factor $\left(a_{t}\right)$ in Columns (1) and (5), external sector-specific factors $\left(\eta_{j, t}\right.$ where $\left.j \neq i\right)$ in Columns (2) and (6), and the GR factor $\left(c_{t}\right)$ in Columns (7), and (9) the overall contribution to volatility of all other sectors by each row sector in Columns (4) and (9). In addition, Column $(3)=(1)+(2)$ and $(8)=(5)+(6)+(7)$ present the combined contribution of external shocks. Thus 100-(3) and 100-(8) give the fraction of sectoral volatility that is explained by its own shock for each row sector. The left panel uses data for the period of 1948-2006 and the right panel uses data for the period of 2007-2012. The calculation is based on a 3-year-ahead forecast error variance decomposition, using the dynamic factor model in (13), with the matrices $\Pi_{0}$ and $\Pi_{1}$ determined by parameters in $\vartheta$ whose values are either from the literature or estimated using using BEA 2002 input-use table and capital flow table. Shocks identified by the loading matrix $S_{1}$ and $S_{2}$ in (7) for the pre-GR and Great Recession periods respectively. 
Table V: Selected summary statistics of the data and various models, pre-GR and GR periods

\begin{tabular}{|c|c|c|c|c|c|c|c|c|c|}
\hline \multirow[t]{2}{*}{ Model } & \multirow[t]{2}{*}{ Shocks } & \multicolumn{2}{|c|}{ Variability $\left(\mathrm{SD}, \sigma_{y}\right)$} & \multicolumn{2}{|c|}{ Avg. Corr. $(\bar{\rho})$} & \multicolumn{2}{|c|}{ RMSE (\%) } & \multicolumn{2}{|c|}{ Spillover Index (\%) } \\
\hline & & Pre-GR & GR & Pre-GR & GR & Pre-GR & GR & Pre-GR & GR \\
\hline Data & & 2.69 & 5.23 & 0.26 & 0.45 & & & & \\
\hline \multirow{4}{*}{$\begin{array}{l}\text { Hybrid } \\
\text { (Benchmark) }\end{array}$} & Total & 2.47 & 4.81 & 0.27 & 0.44 & 14.72 & 22.97 & 50.75 & 76.03 \\
\hline & Aggregate & $39.71 \%$ & $10.51 \%$ & & & & & 22.93 & 12.21 \\
\hline & Sectoral & $60.29 \%$ & $14.36 \%$ & & & & & 27.83 & 16.09 \\
\hline & GR & - & $75.13 \%$ & & & & & - & 47.72 \\
\hline \multirow[t]{4}{*}{ FSW } & Total & 3.46 & 5.31 & 0.38 & 0.52 & 29.70 & 28.71 & 38.84 & 70.42 \\
\hline & Aggregate & $65.61 \%$ & $27.86 \%$ & & & & & 34.30 & 27.52 \\
\hline & Sectoral & $34.39 \%$ & $5.57 \%$ & & & & & 4.54 & 3.02 \\
\hline & GR & - & $66.57 \%$ & & & & & - & 39.87 \\
\hline \multirow{4}{*}{$\begin{array}{l}\text { Dupor } \\
\text {-Horvath }\end{array}$} & Total & 4.80 & 4.86 & 0.47 & 0.47 & 26.67 & 26.23 & 51.56 & 71.39 \\
\hline & Aggregate & $91.14 \%$ & $88.85 \%$ & & & & & 48.52 & 48.31 \\
\hline & Sectoral & $8.86 \%$ & $6.35 \%$ & & & & & 3.04 & 3.98 \\
\hline & GR & - & $4.79 \%$ & & & & & - & 19.11 \\
\hline \multirow{4}{*}{$\begin{array}{l}\text { Long } \\
\text {-Plosser }\end{array}$} & Total & 4.83 & 5.97 & 0.48 & 0.60 & 28.64 & 31.52 & 54.38 & 79.89 \\
\hline & Aggregate & $96.81 \%$ & $63.34 \%$ & & & & & 53.41 & 42.79 \\
\hline & Sectoral & $3.19 \%$ & $0.92 \%$ & & & & & 0.98 & 0.50 \\
\hline & GR & - & $35.74 \%$ & & & & & - & 36.60 \\
\hline
\end{tabular}

Notes: The table compares the standard deviation of real aggregate output growth $\left(\sigma_{y}\right)$, and the average pairwise correlation and associated RMSE $(\%)$ between sectoral growth rates $(\bar{\rho})$ from the data and from the estimated models for the pre-GR and Great Recession periods. The variance of aggregate growth is then decomposed into the contributions by aggregate shocks, sectoral shocks and GR shocks. The pre-GR standard deviations are based on annual percentage growth rates from 1948 to 2006, whereas the corresponding crisis quantities are based on annualized quarterly percentage growth rates from 2007Q1 to 2012Q2. Volatility of aggregate output for the data and the models are based on constant weights over the period 1948 to 2016. The last two columns present the Diebold-Yilmaz spillover indices and their decompositions. based on different models. 
Figure I: Distribution of Sector-pair Correlations, Pre-Great Recession vs. Great Recession

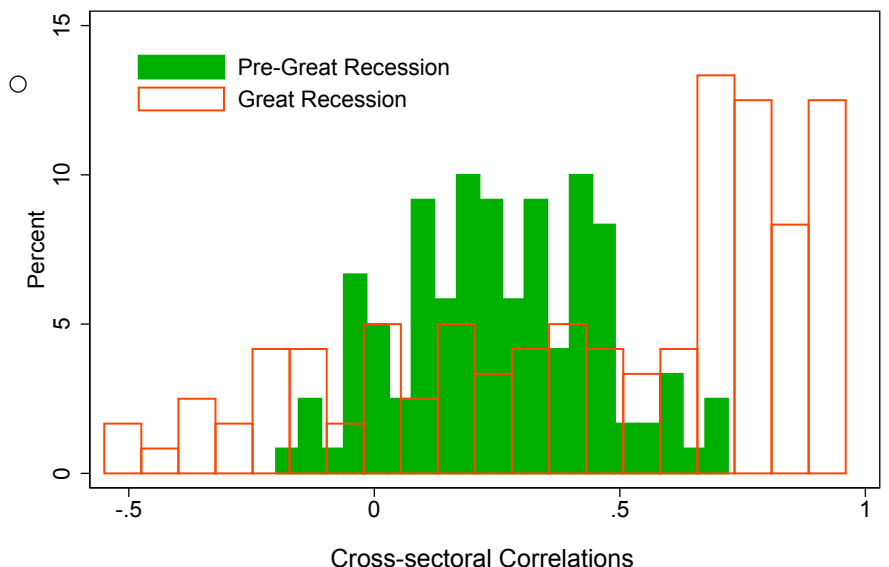

Notes: This figure shows the distribution of cross-sectoral correlations of output growth between 2-3 digit nonfarm business sectors, for the pre-Great Recession period (1948-2006) and the Great Recession (2007Q1-2012Q2), respectively. Data source: 2017 May revised version of GDP-by-Industry Data provided by U.S. BEA.

Figure II: Estimated factors and contributions during the Great Recession based on the Hybrid Model

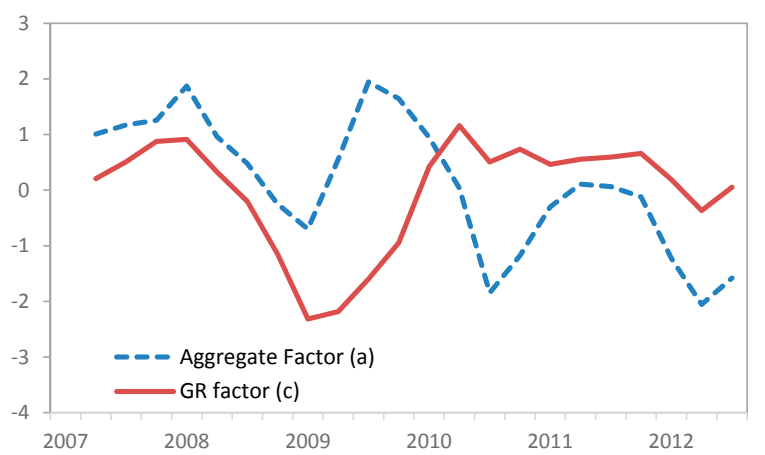

(a) Factors

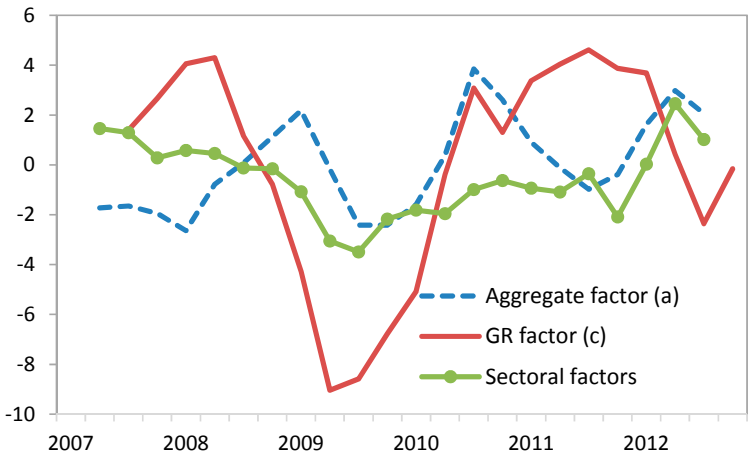

(b) Contributions 
Figure III: Counterfactual Aggregate Output (Without the GR Factor)

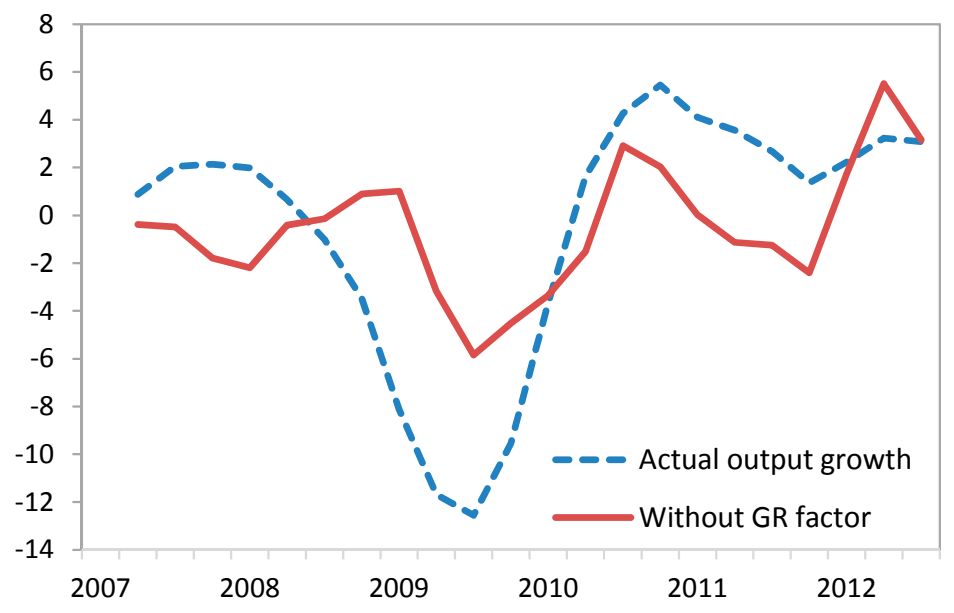

Notes: A counterfactual experiment is conducted by excluding the wedge factor from the hybrid model during the crisis period and reconstructing aggregate GDP from all of the remaining factors.

Figure IV: Correlations of cross-sector sectoral growth before and during the Great Recession
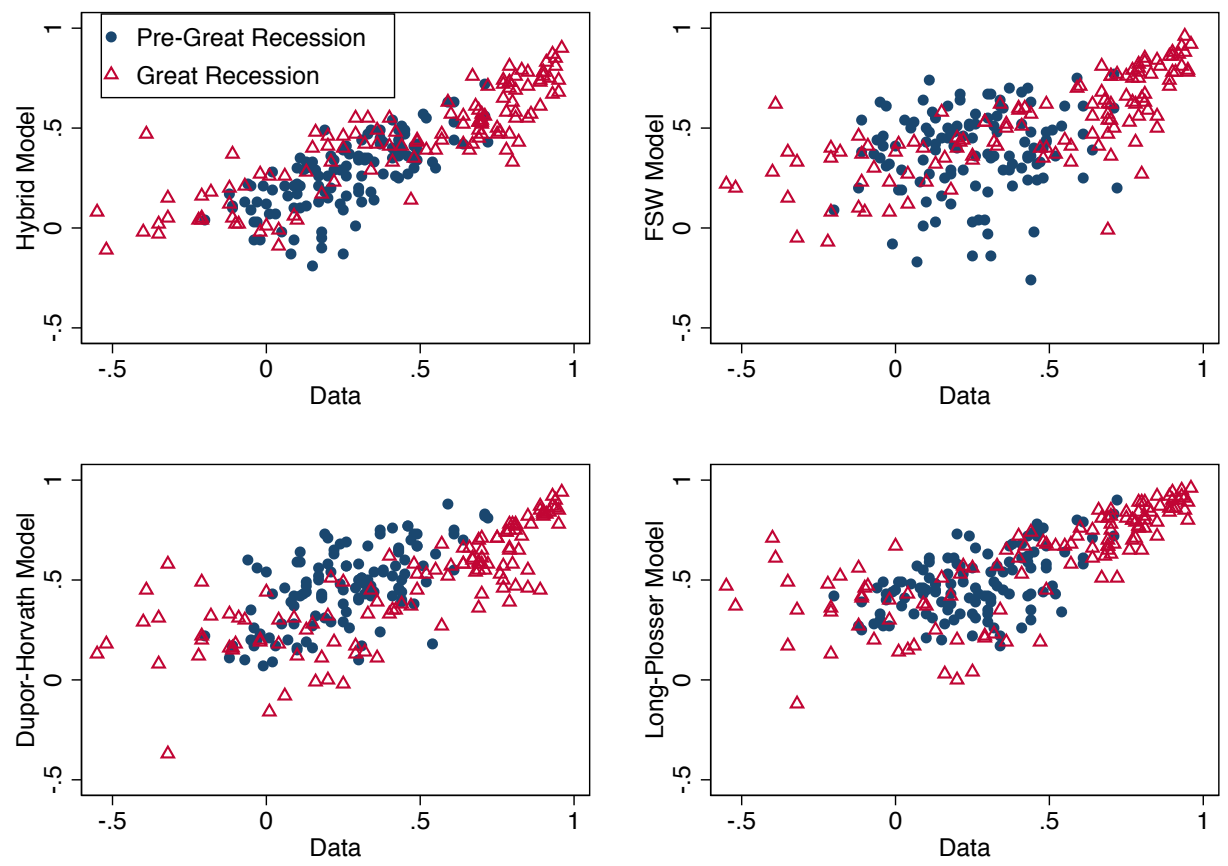
Figure V: Estimated density distribution of cross-variance shares (spillovers) during the Great Recession

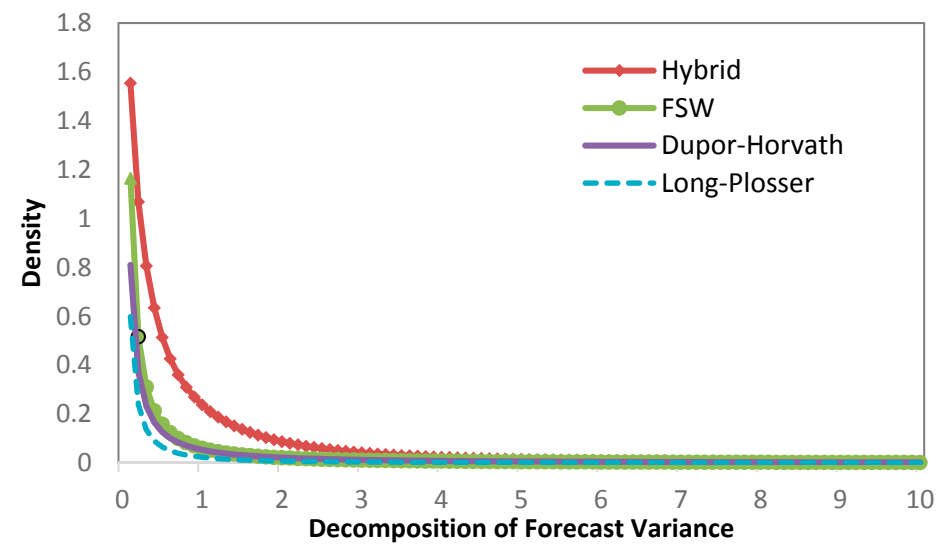

Notes: Cross variance shares (or Diebold-Yilmaz spillovers) are the estimated (percentage) contribution to the 3period-ahead forecast error variance of output growth in sector $i$ coming from shocks to sector $j$, for $i, j=1,2, \ldots, 16$ and $i \neq j$.

Figure VI: Cumulative Contribution to Volatility in Other Sectors for Selected Sectors, Based on hybrid model during the Great Recession

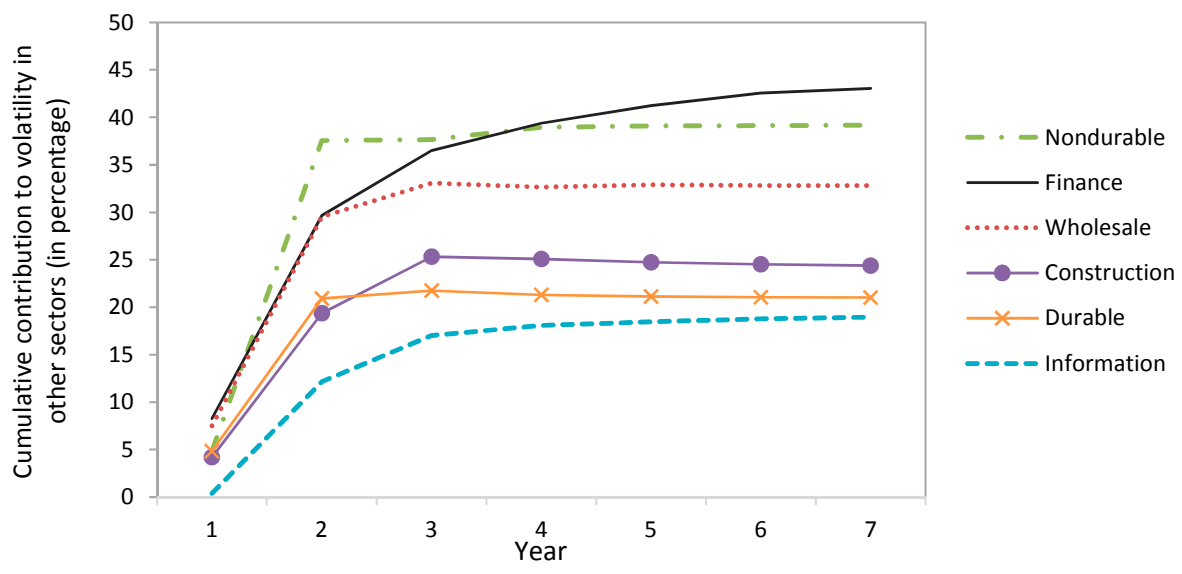

Notes: The figure shows the sum of the estimated (percentage) contribution to the x-period-ahead forecast error variance of output growth in all other sectors coming from shocks to selected sectors including Construction, Nondurable Manufacturing, Finance and Professional Services. 


\section{A Data Sources}

Data on sectoral output are obtained from the Bureau of Economic Analysis (BEA) Industry Account Dataset (May 2017 version). It provides annual series of nominal and real (chain-type, base year 2005) gross output at NAICS 2-4 digit level from 1947 to 2016. We focus on broadly-defined 2-digit level NAICS private business sectors except when there is a meaningful disaggregation for the question at hand. The BEA also provides quarterly seasonally adjusted data from 2005Q1 to 2015Q1. As quarterly data contain more information, especially for the crisis period, in our dynamic factor analysis we make use of both annual and annualized quarterly data. In addition, sectoral shares are calculated as the ratio between nominal sectoral output and total output.

We obtain the benchmark input-output tables from the BEA. The input-use table shows the dollar value (at the producers' price) of inputs from each industry (row) to production in each industry (columns), as well as payments to labor and capital. The industries are defined according to NAICS industry definition at the 4-digit level, which are then aggregated into the 16 sectors. We then obtain a 16-by-16 matrix of input-output linkages. We consider the pre-crisis table for 2002 as a benchmark table, and use the table for 2009 to check for robustness. Similarly, data on compensation of employees (payment to labor) and value-added are also aggregated to the same level of industries. Thus, the capital share of a sector is calculated as value-added less compensation of employees over total output, and the labor share of a sector is calculated as compensation of employees divided by total output.

\section{B A Multi-Sector Model With Input-Output Linkages}

\section{B.1 Model Environment}

The structural model is similar to Foester et al. (2011) which is a canonical model with sectoral input-output linkages. It consists of an economy populated by a large number of identical, infinitely lived households, who maximize their expected lifetime discounted utility over consumption and leisure:

$$
E_{0} \sum_{t=0}^{\infty} \beta^{t}\left(\log C_{t}-\psi L_{t}\right),
$$

where $\beta$ denotes the discount factor, $\psi$ governs the preference for leisure, and $L_{t}$ is the labor input. The aggregate consumption good $C_{t}$ is a Cobb-Douglas combination of sectoral goods:

$$
C_{t}=B \prod_{j=1}^{N} C_{j t}^{\theta_{j}},
$$

where $C_{j t}$ denotes consumption of good $j$ per capita in period $t$, and $\theta_{j}$ governs the preference weight and $\sum_{j=1}^{N} \theta_{j}=1$. $B$ is a constant.

Each sectoral good is produced using sector-specific capital, labor and a set of intermediate inputs, and also serves as a potential input in producing another sectoral good. The production technology follows a Cobb-Douglas, constant return to scale production function in the following fashion:

$$
Y_{j t}=Z_{j t} K_{j t}^{\varphi_{j}} L_{j t}^{\alpha_{j}} \prod_{j=1}^{N} M_{i j t}^{\gamma_{i j}},
$$

where $K_{i t}$ and $L_{j t}$ are the capital and labor inputs of sector $j$, respectively. The input $M_{i j}$ denotes 
the amount of good $i$ used in production of good $j$ and the share of input from sector $i$ in total cost of production in sector $j$ is given by $\gamma_{i j}$. An input-use matrix is defined as a $N \times N$ matrix $\Gamma$ with typical element $\gamma_{i j}$. The row sectors are the input suppliers and the column sectors are the input purchasers. The parameters $\alpha_{j}$ and $\varphi_{j}$ govern the share of labor and capital input in production, respectively. The assumption of constant returns to scale in each sector implies $\alpha_{j}+\varphi_{j}+\sum_{i=1}^{N} \gamma_{i j}=1$. Assume that the productivity in sector $j, Z_{j t}$, follows a random walk:

$$
\log \left(Z_{j t}\right)=\log \left(Z_{j t-1}\right)+\mu_{j t}
$$

where shocks to the sectoral productivity, $\mu_{j t}$, comprise common shocks, $a_{t}$, and independent sectorspecific shocks, $\varepsilon_{j t}$ :

$$
\mu_{j t}=\lambda_{j} a_{t}+\xi_{j t}
$$

The parameter $\lambda_{j}$ governs the exposure of the sectoral productivity shocks to the aggregate shocks. We assume that $a_{t} \sim N\left(0, \sigma_{a}^{2}\right), \xi_{j t} \sim N\left(0, \sigma_{\xi_{j}}^{2}\right)$, and $\rho\left(\xi_{i t}, \xi_{j t}\right)=0, \rho\left(a_{t}, \xi_{j t}\right)=0$.

In addition, the capital in sector $i$ accumulates according to $K_{j t+1}=I_{j t}+\left(1-\delta_{d}\right) K_{j t}$, where $\delta_{d}$ is the depreciation rate. Sectoral investment $I_{j t}$ is produced by employing a Cobb-Douglas technology using $Q_{i j t}$ amount of sector $i$ good:

$$
I_{j t}=\prod_{i=1}^{N} Q_{i j t}^{\psi_{i j}}, \quad \sum_{i=1}^{N} \psi_{i j}=1 .
$$

where $\theta_{i j}$ denotes the element of capital use matrix, the share of input from sector $i$ in total investment in sector $j$.

The sectoral resource constraint in the goods market is:

$$
C_{j t}+Q_{j i t}+\sum_{i=1}^{N} M_{j i t}=Y_{j t}, \quad \forall j
$$

The labor market clearing condition implies

$$
\sum_{j=1}^{N} L_{j t}=L_{t}
$$

\section{B.2 Influence Factors and Aggregate Volatility}

For illustrative purposes, let us consider first a static variant of the model where there is no capital. The production function in (24) is now given by $Y_{j t}=Z_{j t} L_{j t}^{\alpha_{j}} \prod_{i=1}^{N} M_{i j t}^{\gamma_{i j}}$, where the aggregate income is now equal to the labor income, i.e. $P_{t} Y_{t}=W_{t} L_{t}$. The derivation is similar to Acemoglu et al. (2013) and Carvalho (2010) except that we allow sectors to also differ in their expenditure shares in final consumption and we consider total factor productivity instead of labor-augmenting productivity. We show that the model's assumptions of Cobb-Douglas production function and further assumption that $\psi=0$ admit a linear relationship between aggregate output growth and sectoral productivity growth for each period. In particular, aggregate growth is the weighted sum of sectoral productivity growth with weight given by a centrality measure based on the input-output linkages.

Definition 1 A competitive equilibrium of the economy is defined as a time series of prices including sectoral goods prices $\left\{P_{j t}\right\}_{j=1, \ldots, N}$, wage $W_{t}$, a set of quantities including consumption 
bundle $\left\{C_{j t}\right\}_{j=1, \ldots, N}$, labor supply $\left\{L_{j t}\right\}_{j=1, \ldots, N}$, sectoral output $\left\{Y_{j t}\right\}_{j=1, \ldots, N}$ and intermediate input $\left\{M_{i j t}\right\}_{i, j=1, \ldots, N}$ such that (i) households maximize their life time utility; (ii) firms in each sector maximize profits; and (iii) labor and goods market clear:

$$
\begin{aligned}
\sum_{j=1}^{N} L_{j t} & =1 \\
C_{j t}+\sum_{i=1}^{N} M_{j i t} & =Y_{j t}, \quad j=1, \ldots, N .
\end{aligned}
$$

The first order conditions with respect to labor and intermediate input imply:

$$
\begin{aligned}
L_{j t} & =\alpha_{j} \frac{P_{j t} Y_{j t}}{W_{t}}, \\
M_{i j t} & =\gamma_{i j} \frac{P_{j t} Y_{j t}}{P_{i t}} .
\end{aligned}
$$

Substituting these expressions back into the sectoral production function and re-arranging the terms, we have:

$$
\alpha_{j} \log W_{t}=\log \left(Z_{j t}\right)+\alpha_{j} \log \alpha_{j}+\log P_{j t}+\sum_{i=1}^{N} \gamma_{i j} \log \gamma_{i j}-\sum_{i=1}^{N} \tau_{i j} \log P_{i t} .
$$

Utility maximization of the household over consumption bundles implies $P_{j t} C_{j t}=\theta_{j} P_{t} Y_{t}=$ $\theta_{j} W_{t}$. Together with the goods market clearing condition (31), we obtain:

$$
\frac{P_{j t} Y_{j t}}{W_{t}}=\theta_{j}+\sum_{i=1}^{N} \gamma_{j i} \frac{P_{i t} Y_{i t}}{W_{t}}
$$

Defining the influence factor as $v_{j t}=\frac{P_{j t} Y_{j t}}{W_{t}}$, we then have

$$
v_{j t}=\theta_{j}+\sum_{i=1}^{N} \gamma_{j i} v_{i t}
$$

Intuitively, the value or influence of sector $j$ in the economy depends upon not only its share in consumption expenditure, $\theta_{j}$, but also its importance as an input supplier (captured by the second term of (35)), which is a linear combination of the influences of its immediate downstream sectors, $v_{i t}$. Thus, a sector, acting as an important input supplier (higher $\gamma_{j i}$ ) to an 'influential' sector, is itself important in contributing to aggregate output fluctuations. As there are no timedependent variables other than $v_{j t}$ that enter the iterative system of $(35), v_{j t}$ is time-invariant, i.e. $v_{j t}=v_{j}, \forall j$. Thus, we obtain (2) as in Section 2.2. In addition, the definition of $v_{j}$ implies $v_{j}=\frac{L_{j, t}}{\alpha_{j}}$ and $\sum_{j=1}^{N} v_{j}=1$. Together with the labor market clearing condition in (30), this implies that $\sum_{i=1}^{N} \alpha_{i} v_{i}=1$.

Now multiplying both sides of (32) by $v_{j}$ and summing over all sectors yields:

$$
\log P_{t} Y_{t}=\log W_{t}=\sum_{j=1}^{N} v_{j} \log \left(Z_{j t}\right)+\sum_{j=1}^{N} v_{j} \alpha_{j} \log \left(\alpha_{j}\right)+\sum_{j=1}^{N} \theta_{j} \log P_{j t}+\sum_{j=1}^{N} \sum_{j=1}^{N} v_{j} \gamma_{i j} \log \gamma_{i j} .
$$


By normalizing the aggregate price index $P=1$, the equilibrium price consistent with (23) implies $\log B=\sum_{j=1}^{N} \theta_{j} \log P_{j}$. As $\log B=-\sum_{j=1}^{N} v_{j}\left(\alpha_{j} \log \left(\alpha_{j}\right)+\sum_{i=1}^{N} \gamma_{i j} \log \gamma_{i j}\right)$, we get:

$$
\log Y_{t}=\sum_{j=1}^{N} v_{j} \log \left(Z_{j t}\right),
$$

which implies equation (1).

Based on (26) and (37), we can conveniently express the volatility of aggregate output as:

$$
\sigma_{y}^{2}=\left(\sum_{j=1}^{N} v_{j} \lambda_{j}\right)^{2} \sigma_{a}^{2}+\sum_{j=1}^{N} v_{j}^{2} \sigma_{\xi_{j t}}^{2} .
$$

This equation highlights that the overall volatility of the economy is closely related to the pattern of the input-output structure between different sectors.

Suppose intersectoral linkages are negligible $\left(\gamma_{j i}=0\right)$ or symmetric $\left(\gamma_{j i}=\gamma\right), v_{i}$ becomes proportional to $\theta_{i}$. It is easy to show that (3) in this simple economy encompasses two contrasting cases. The first case is Gabaix's granular economy in which sectors are highly heterogeneous in terms of sizes and sectoral productivities are uncorrelated $\left(\sigma_{a}=0\right)$. In such an economy, fluctuations in large sectors drive the aggregate volatility. On the other hand, if sectors are similar in size and sectoral productivity are correlated as in Lucas' (1977) world, then idiosyncratic sectoral shocks tend to average out and have little impact on aggregate output when the number of sectors gets larger. The roles played by sector-specific shocks and common shocks are vastly different in this two cases.

Using the 2002 input-use and capital flow tables from the BEA, we estimate $v_{i}$ and compare it with the relative sector size (in Figure A.1)

Figure A.1: Sector sizes and influence factors

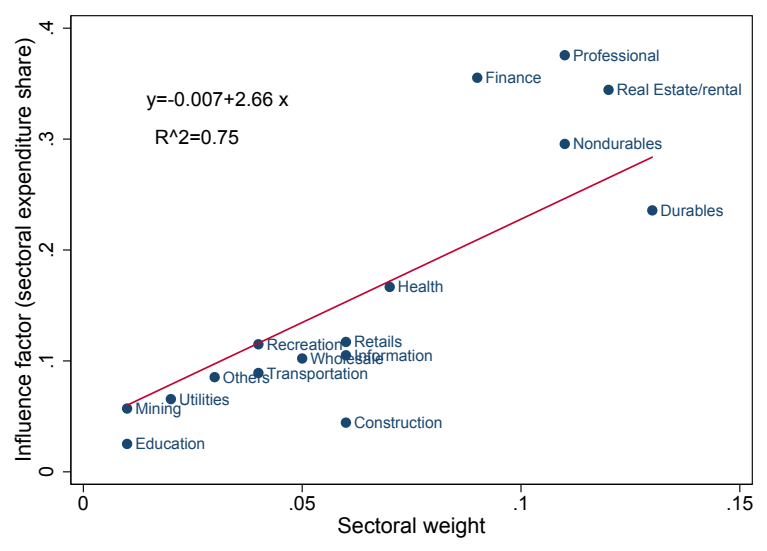

(a) Unequal $\theta_{i}$

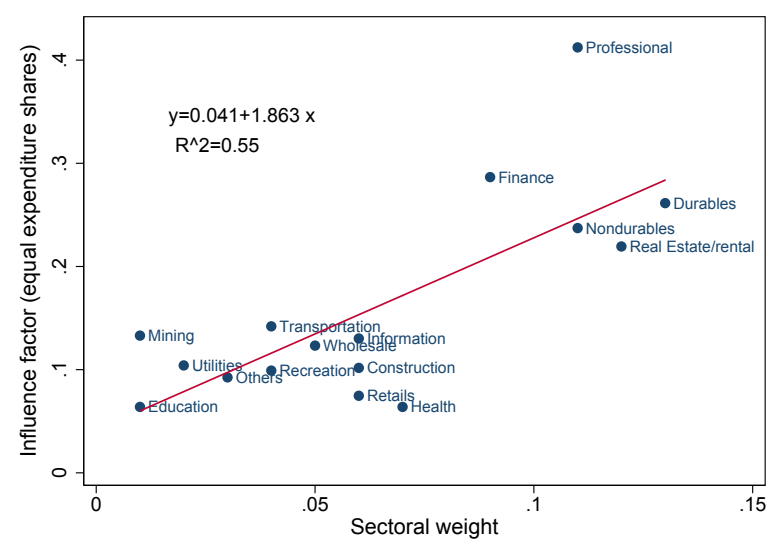

(b) Equal $\theta_{i}=\bar{\theta}$

Notes: Influence factors for each sectors are calculated based on Equation (2), where $\theta_{i}=$ share of consumption expenditure $i$ in (a) and $\theta_{i}=$ average share of sales, $\bar{\theta}$, in (b). Sectoral weight is calculated as sectoral output share. 


\section{Additional Results}

\section{C.1 Preliminary Tests}

As a preliminary test of the model's factor structure, Table A.1 presents the results from performing the Bai-Ng (2002) information criteria set of tests to determine the optimal number of factors amongst the growth rates of the 16 sectors. The results are presented for two sample periods: the pre-GR period and the period of the Great Recession. The results of the tests provide strong evidence of a single common factor operating during each of the two sample periods investigated. The factor loadings on the first principal component corresponding to both sample periods are given in Table A.2. The structure of the factor loadings on the first principle component suggests that it reflects an economy-wide factor with positive contributions from all sectors with roughly similar magnitudes, with the exception of Health Care and Education, where the estimated loadings are relatively smaller than the loadings obtained for the other sectors in the pre-GR factor, and even negative in the case of the GR factor.

Table A.1: Bai-Ng information criteria tests of the number of factors

\begin{tabular}{|c|c|c|c|c|c|c|c|c|c|}
\hline \multirow{2}{*}{$\begin{array}{c}\text { Number of } \\
\text { Factors }\end{array}$} & \multicolumn{3}{|c|}{ Total } & \multicolumn{3}{|c|}{$\begin{array}{l}\text { Pre-GR } \\
\end{array}$} & \multicolumn{3}{|c|}{ GR } \\
\hline & $I C_{1}$ & $I C_{2}$ & $I C_{3}$ & $I C_{1}$ & $I C_{2}$ & $I C_{3}$ & $I C_{1}$ & $I C_{2}$ & $I C_{3}$ \\
\hline 1 & 0.6240 & 0.6401 & 0.5999 & 0.4235 & 0.4426 & 0.3956 & 1.3235 & 1.3825 & 1.2565 \\
\hline 2 & 0.7534 & 0.7855 & 0.7051 & 0.5393 & 0.5774 & 0.4834 & 1.5305 & 1.6485 & 1.3964 \\
\hline 3 & 0.8948 & 0.9429 & 0.8224 & 0.6592 & 0.7164 & 0.5754 & 1.7405 & 1.9176 & 1.5395 \\
\hline 4 & 1.0416 & 1.1058 & 0.9451 & 0.7836 & 0.8599 & 0.6719 & 1.9578 & 2.1938 & 1.6897 \\
\hline 5 & 1.1910 & 1.2712 & 1.0703 & 0.9129 & 1.0082 & 0.7732 & 2.1896 & 2.4846 & 1.8545 \\
\hline
\end{tabular}

Notes: Bai-Ng information criteria tests of the number of factors for alternative sample periods. The total period (1948-2016) and the pre-GR period (1948-2006) are based on annual data, and the period of the Great Recession (2007Q1-2012Q2) which is based on quarterly data.

Table A.2 shows that the proportion of the total variation in the 16 growth rates explained by the first principal component during the pre-GR period is just over $45 \%$. However, the contribution of this factor to aggregate volatility is over $97 \%$, thereby giving more evidence in favor of a single common factor in determining aggregate output in the US. Formally, this decomposition is computed as $w^{\prime} \Lambda \Lambda^{\prime} w / \sigma_{y}^{2}$, where $w$ is the vector of sectoral weights in determining aggregate output, $\Lambda$ is the vector containing the loadings of the one-factor model reported in Table A.2 and $\sigma_{y}^{2}$ is the variance of aggregate volatility which for commensurability is also computed using the same weights.

Inspection of the loadings in Table A.2 on the common factor during the Great Recession reveals important changes in its properties when compared to the common factor operating preGreat Recession. For example, now shocks in the GR common factor have their greatest impact on the Durables and Wholesale sectors. In the case of Education and Health Care the loading estimates are now even negative, although nonetheless relatively small in absolute terms. Moreover, the relative contribution of this factor to overall volatility of the sectoral growth rates during the Great Recession has increased to $76 \%$, suggesting an increase in connectedness amongst the sectoral growth rates. The aggregate output growth volatility is explained by this common factor by around $97 \%$.

In estimating the 16-variate VAR in the first step the full set of annual data on sectoral growth rates covering the total sample period from 1948 to 2016 is used to estimate the parameters deter- 
Table A.2: Factor loadings of the first principal component from a principal components decomposition of the annual sectoral growth rates

\begin{tabular}{lccc}
\hline \hline Industry & Total & Pre-GR & GR \\
\hline Mining & 2.2523 & 2.1830 & 3.5179 \\
Utilities & 2.9684 & 2.1877 & 6.9926 \\
Construction & 4.6427 & 4.4890 & 3.6951 \\
Durables & 6.0403 & 5.6533 & 11.8533 \\
Nondurables & 2.3155 & 2.1597 & 3.4831 \\
Wholesale & 4.3088 & 2.9573 & 12.6238 \\
Retail & 2.8557 & 2.8039 & 4.4462 \\
Transportation & 3.4265 & 3.1800 & 6.2282 \\
Information & 1.3495 & 0.9896 & 2.9447 \\
Finance & 1.5591 & 1.1164 & 1.1311 \\
Real Estate & 1.3058 & 0.8391 & 2.1647 \\
Professional & 2.4491 & 2.2148 & 3.8728 \\
Education & 0.3263 & 0.3795 & -0.0077 \\
Health Care & 0.2892 & 0.1789 & -0.1372 \\
Recreation & 1.4135 & 1.0957 & 2.6460 \\
Other Services & 1.8455 & 1.4930 & 2.7418 \\
\hline Proportion of total sectoral volatility (\%) & 46.6992 & 41.6827 & 76.3454 \\
Proportion of aggregate volatility (\%) & 97.5038 & 97.2688 & 96.6219 \\
\hline \hline
\end{tabular}

Notes: This table reports factor loadings of the first principal component from a principal components decomposition of sectoral growth rates for alternative sample periods. The total period (1948-2016) and the pre-GR period (19482006) which are based on annual data, and the period of the Great Recession (2007Q1-2012Q2) which is based on quarterly data. 
mining the model's dynamics $\Phi$. This strategy, although motivated by degrees of freedom issues from estimating a relatively large dimensional VAR given the size of the sample, implicitly assumes that the dynamics linking sectors does not significantly change during the period of the Great Recession relative to the pre-GR period. To assess the appropriateness of this assumption, we perform a multivariate version of the Diebold and Chen (1996) structural break test in which the timing of the crisis is treated as endogenous. As the distribution of the test statistic is non-standard, bootstrapped $p$-values are constructed by simulating the model under the null hypothesis of no structural break in the dynamics.

Table A.3 presents the results of testing for an endogenous structural break in the model's dynamics for each sector based on the likelihood ratio statistic. The table reports the $p$-values of the Diebold-Chen test based on 50, 000 bootstraps. In bootstrapping the distribution of the test statistic the wild bootstrap of Davidson and Flachaire (2000) is adopted to capture the heteroskedasticity in the disturbance term arising from the presence of increases in volatility during the period of the Great Recession. Two versions of the structural break test are reported to circumvent degrees of freedom issues from applying the endogenous structural break test to the $N=16$ variate VAR. The first is based on a bivariate VAR consisting of the growth rates of a sector and the first principal component of the other 15 sectoral growth rates. The trivariate version of the test is an extension of the bivariate VAR by including the second principal component as well. The bivariate and trivariate models represent multivariate extensions of the Diebold and Chen test which are designed to correct for potential dynamical interdependencies across sectors. The empirical results find little evidence of structural breaks in the dynamics of most of the $N=16$ sectors over the sample period. For the bivariate VAR version of the test there are no significant breaks identified at the $1 \%$ level except for Recreation and for just three sectors at the $5 \%$ level (Nondurables, Retail and Real Estate). In the case of the trivariate version of the test there is no evidence of structural breaks in most sectors with the exception of Construction, Information, Real Estate, Education and Recreation at the $5 \%$ level.

\section{C.2 Diebold-Yilmaz Spillover Tables}

Here we report the full Diebold-Yilmaz Spillover Tables. The $(i, j)$ th entry in the table is the estimated contribution to the forecast error variance of real growth rate in sector $i$ coming from shocks to sector $j$. The shocks are identified by the loading matrix $S_{i}$ in (7) and are based on the hybrid SVAR model. Tables A.4 and A.5 thus contain respectively the pre-2007 and post-2007 3 -year forecast error variance decompositions of the 16 sectors. The off-diagonal entries represent the cross variance shares, or spillovers, and the diagonal gives the own variance shares. Therefore, the sum of each off-diagonal column gives the contribution of that sector (factor) to others and the off-diagonal row sum generates the contribution from other sectors to that sector. The total of the column sums or the row sums thus gives the Diebold-Yilmaz Spillover index. These tables form the bases for Table IV. 
Table A.3: Diebold-Chen endogenous structural break test statistics of the model's dynamics

\begin{tabular}{lcccc}
\hline \hline Industry & \multicolumn{2}{c}{ Bivariate } & \multicolumn{2}{c}{ Trivariate } \\
\hline Mining & Statistic & $p$-value & Statistic & $p$-value \\
Utilities & 13.1887 & 0.4055 & 34.5393 & 0.0548 \\
Construction & 21.2319 & 0.0624 & 33.1503 & 0.0857 \\
Durables & 21.6796 & 0.0530 & 42.0987 & 0.0154 \\
Nondurables & 21.9981 & 0.0386 & 30.6503 & 0.1221 \\
Wholesale & 25.0938 & 0.0139 & 28.6984 & 0.1617 \\
Retail & 20.6256 & 0.0604 & 36.7207 & 0.0410 \\
Transportation & 24.3387 & 0.0193 & 33.1663 & 0.0619 \\
Information & 20.5532 & 0.0770 & 30.4462 & 0.1436 \\
Finance & 21.8450 & 0.0518 & 39.4296 & 0.0197 \\
Real Estate & 19.4755 & 0.0923 & 32.1246 & 0.0939 \\
Professional & 23.0176 & 0.0305 & 36.9934 & 0.0269 \\
Education & 18.3777 & 0.1113 & 29.9567 & 0.1281 \\
Health Care & 19.2304 & 0.1314 & 36.4666 & 0.0493 \\
Recreation & 19.4930 & 0.0948 & 29.2701 & 0.1833 \\
Other Services & 44.1644 & 0.0000 & 59.0794 & 0.0001 \\
\hline \hline
\end{tabular}

Notes: This table reports results from Diebold-Chen endogenous structural break test of the model's dynamics for each sector, 1948-2016: The column headed Bivariate is based on the sector growth rate and the first principal component of the remaining 15 sector growth rates; and the column headed Trivariate is based on the sector growth rate and the first two principal components of the remaining 15 growth rates. The test statistic reported is the likelihood ratio statistic with $p$-values computed using a wild bootstrap with 50,000 bootstrap samples. 
Table A.4: Diebold-Yilmaz Spillover Matrix: variance decomposition of sectoral output growth (1948 to 2006)

\begin{tabular}{|c|c|c|c|c|c|c|c|c|c|c|c|c|c|c|c|c|c|}
\hline \multirow[b]{2}{*}{ To } & \multicolumn{17}{|c|}{ From } \\
\hline & Agg. & Mining & Util. & Const. & Dur. & Nondur. & Whole. & Retail & Trans. & Info. & Fin. & $\mathrm{RE}$ & Prof. & Edu. & Health & Rec. & Other \\
\hline Mining & 42.44 & 38.95 & 0.21 & 0.16 & 2.07 & 1.31 & 1.58 & 0.68 & 0.08 & 0.64 & 0.33 & 3.90 & 2.19 & 0.74 & 1.83 & 0.60 & 2.28 \\
\hline Utilities & 6.66 & 3.71 & 60.35 & 1.96 & 1.33 & 2.81 & 0.69 & 0.35 & 3.58 & 4.03 & 2.47 & 2.76 & 1.31 & 0.82 & 5.84 & 0.56 & 0.76 \\
\hline Construction & 17.76 & 2.04 & 0.25 & 52.66 & 5.06 & 1.49 & 0.98 & 0.28 & 0.63 & 1.60 & 3.38 & 0.69 & 1.09 & 1.27 & 4.41 & 1.06 & 5.35 \\
\hline Durables & 43.61 & 3.96 & 0.29 & 3.50 & 29.62 & 2.08 & 1.52 & 0.96 & 0.57 & 0.36 & 0.62 & 2.33 & 1.27 & 2.69 & 2.98 & 1.15 & 2.48 \\
\hline Nondurables & 1.96 & 5.19 & 1.79 & 2.74 & 8.84 & 57.55 & 1.69 & 0.68 & 1.19 & 0.45 & 2.17 & 6.33 & 3.17 & 0.78 & 1.35 & 0.39 & 3.76 \\
\hline Wholesale & 51.08 & 0.14 & 0.69 & 0.18 & 1.55 & 1.12 & 28.73 & 1.47 & 0.77 & 1.85 & 3.52 & 4.61 & 0.81 & 0.21 & 2.86 & 0.33 & 0.10 \\
\hline Retail & 32.93 & 1.21 & 0.18 & 3.61 & 0.79 & 0.73 & 1.39 & 47.73 & 4.26 & 0.71 & 0.85 & 0.15 & 0.56 & 0.27 & 1.25 & 2.00 & 1.37 \\
\hline Transportation & 21.93 & 3.49 & 0.19 & 1.01 & 1.96 & 5.00 & 1.60 & 1.31 & 56.42 & 0.89 & 0.77 & 1.55 & 0.55 & 0.25 & 1.01 & 0.71 & 1.35 \\
\hline Information & 18.09 & 1.56 & 0.66 & 0.29 & 1.71 & 1.12 & 0.33 & 2.69 & 0.58 & 58.82 & 8.20 & 0.36 & 3.30 & 0.52 & 1.50 & 0.16 & 0.12 \\
\hline Finance & 19.27 & 0.45 & 3.63 & 0.91 & 0.20 & 1.80 & 0.18 & 1.43 & 1.02 & 14.11 & 48.66 & 1.44 & 1.75 & 1.01 & 0.94 & 2.73 & 0.46 \\
\hline Real Estate & 18.51 & 1.19 & 0.13 & 3.06 & 2.23 & 3.62 & 1.07 & 1.78 & 0.38 & 0.81 & 3.72 & 58.76 & 1.92 & 0.22 & 1.52 & 0.17 & 0.90 \\
\hline Professional & 25.29 & 2.85 & 0.56 & 2.43 & 3.89 & 3.12 & 1.09 & 0.51 & 1.60 & 1.47 & 7.56 & 1.22 & 38.97 & 1.75 & 3.23 & 1.90 & 2.57 \\
\hline Education & 18.83 & 0.38 & 2.13 & 6.44 & 0.06 & 7.59 & 0.30 & 0.30 & 2.67 & 0.43 & 6.12 & 1.15 & 5.71 & 44.58 & 0.66 & 0.25 & 2.41 \\
\hline Health & 1.12 & 0.12 & 0.51 & 2.83 & 6.83 & 8.28 & 1.64 & 0.01 & 0.32 & 0.44 & 1.20 & 1.05 & 3.59 & 1.66 & 65.53 & 2.78 & 2.10 \\
\hline Recreation & 20.51 & 1.68 & 1.27 & 0.41 & 1.21 & 1.97 & 1.74 & 0.01 & 1.55 & 1.64 & 5.21 & 1.03 & 1.45 & 1.89 & 3.07 & 55.22 & 0.13 \\
\hline Other Services & 26.82 & 0.05 & 1.18 & 0.85 & 2.20 & 8.94 & 0.33 & 0.18 & 1.84 & 1.47 & 5.31 & 0.89 & 2.87 & 0.48 & 0.15 & 1.04 & 45.40 \\
\hline
\end{tabular}

es: The underlying variance decomposition is based on a 3-year-ahead forecast horizon with shocks identified by the loading matrix $S_{1}$ in $(7)$. The $(i, j)$ th entry represents the estimated contribution to the variance of the 3-year ahead real output growth forecast error of sector $i$ (row sector) coming from shocks to sector $j$ (column sector) or shocks to the aggregate economy. 
Table A.5: Diebold-Yilmaz Spillover Matrix: variance decomposition of sectoral output growth (2007 to 2012).

\begin{tabular}{|c|c|c|c|c|c|c|c|c|c|c|c|c|c|c|c|c|c|c|}
\hline \multirow[b]{2}{*}{ To } & \multicolumn{18}{|c|}{ From } \\
\hline & Agg. & Mining & Util. & Const. & Dur. & NonD. & Whole. & Retail & Trans. & Info. & Fin. & $\mathrm{RE}$ & Prof. & Edu. & Health & Rec. & Other & GR \\
\hline Mining & 33.76 & 21.06 & 0.25 & 0.15 & 1.14 & 0.88 & 3.93 & 0.28 & 0.04 & 0.48 & 0.31 & 2.93 & 0.59 & 0.68 & 0.17 & 0.18 & 1.15 & 32.04 \\
\hline Utilities & 3.59 & 1.36 & 48.63 & 1.26 & 0.50 & 1.28 & 1.16 & 0.10 & 1.30 & 2.02 & 1.57 & 1.41 & 0.24 & 0.52 & 0.36 & 0.11 & 0.26 & 34.33 \\
\hline Construction & 15.21 & 1.18 & 0.31 & 53.43 & 3.00 & 1.08 & 2.62 & 0.12 & 0.36 & 1.27 & 3.41 & 0.56 & 0.32 & 1.26 & 0.43 & 0.34 & 2.90 & 12.20 \\
\hline Durables & 12.40 & 0.76 & 0.12 & 1.18 & 5.82 & 0.50 & 1.34 & 0.14 & 0.11 & 0.09 & 0.21 & 0.63 & 0.12 & 0.89 & 0.10 & 0.12 & 0.45 & 75.02 \\
\hline Nondurables & 0.67 & 1.20 & 0.91 & 1.11 & 2.08 & 16.51 & 1.80 & 0.12 & 0.27 & 0.14 & 0.87 & 2.04 & 0.37 & 0.31 & 0.05 & 0.05 & 0.81 & 70.69 \\
\hline Wholesale & 14.05 & 0.03 & 0.28 & 0.06 & 0.29 & 0.26 & 24.62 & 0.21 & 0.14 & 0.47 & 1.14 & 1.20 & 0.08 & 0.07 & 0.09 & 0.03 & 0.02 & 56.97 \\
\hline Retail & 14.31 & 0.36 & 0.11 & 1.86 & 0.24 & 0.27 & 1.89 & 10.64 & 1.24 & 0.29 & 0.43 & 0.06 & 0.08 & 0.14 & 0.06 & 0.32 & 0.38 & 67.32 \\
\hline Transportation & 7.17 & 0.78 & 0.09 & 0.39 & 0.44 & 1.38 & 1.63 & 0.22 & 12.40 & 0.27 & 0.30 & 0.48 & 0.06 & 0.09 & 0.04 & 0.09 & 0.28 & 73.90 \\
\hline Information & 6.42 & 0.38 & 0.35 & 0.12 & 0.42 & 0.33 & 0.36 & 0.49 & 0.14 & 19.37 & 3.42 & 0.12 & 0.40 & 0.21 & 0.06 & 0.02 & 0.03 & 67.37 \\
\hline Finance & 11.42 & 0.18 & 3.21 & 0.64 & 0.08 & 0.90 & 0.34 & 0.44 & 0.41 & 7.77 & 33.96 & 0.81 & 0.35 & 0.70 & 0.06 & 0.60 & 0.17 & 37.97 \\
\hline Real Estate & 10.53 & 0.46 & 0.11 & 2.06 & 0.88 & 1.73 & 1.89 & 0.52 & 0.14 & 0.43 & 2.49 & 31.59 & 0.37 & 0.14 & 0.10 & 0.04 & 0.32 & 46.18 \\
\hline Professional & 12.27 & 0.94 & 0.41 & 1.40 & 1.31 & 1.27 & 1.65 & 0.13 & 0.52 & 0.66 & 4.32 & 0.56 & 6.40 & 0.98 & 0.18 & 0.34 & 0.79 & 65.88 \\
\hline Education & 17.73 & 0.24 & 2.99 & 7.18 & 0.04 & 6.01 & 0.87 & 0.14 & 1.69 & 0.38 & 6.78 & 1.02 & 1.82 & 48.60 & 0.07 & 0.09 & 1.44 & 2.92 \\
\hline Health & 2.26 & 0.16 & 1.53 & 6.78 & 9.56 & 14.11 & 10.35 & 0.02 & 0.44 & 0.83 & 2.85 & 2.01 & 2.46 & 3.89 & 15.25 & 2.09 & 2.69 & 22.70 \\
\hline Recreation & 8.70 & 0.48 & 0.81 & 0.21 & 0.36 & 0.70 & 2.30 & 0.00 & 0.44 & 0.65 & 2.60 & 0.41 & 0.21 & 0.93 & 0.15 & 8.69 & 0.04 & 72.32 \\
\hline Other Services & 24.84 & 0.03 & 1.62 & 0.93 & 1.41 & 6.97 & 0.96 & 0.08 & 1.15 & 1.27 & 5.78 & 0.78 & 0.90 & 0.52 & 0.02 & 0.36 & 26.62 & 25.77 \\
\hline
\end{tabular}

Notes: The underlying variance decomposition is based on a 3-year-ahead forecast horizon with shocks identified by the loading matrix $S_{1}$ in $(7)$. The $(i, j)$ th entry represents the estimated contribution to the variance of the 3 -year ahead real output growth forecast error of sector $i$ (row sector) coming from shocks to sector $j$ (column sector) or shocks to the aggregate economy. 


\section{C.3 Robustness Checks: Results}

This appendix provides the results of four robustness checks as summarized in Section 6 .

Changes in the Input-Output Matrix To investigate the effect of changes in the input-output matrix before and after the Great Recession, we consider two input-use matrices in estimating the Hybrid SVAR in (13). For the pre-GR period we still use the BEA benchmark I-O matrix from $2002\left(\Gamma^{2002}\right)$, whereas for the period of the Great Recession instead the I-O matrix from 2009 $\left(\Gamma^{2009}\right)$ is now adopted. Table A.6 summarizes the parameter estimates of the factor loadings of the Hybrid SVAR model using different I-O tables for the two subsamples. Comparing with the previous estimates in Table II, which assumes no changes in the I-O linkages, shows that both estimated models yield very similar results as regards signs and magnitudes.

Table A.6: Maximum likelihood parameter estimates of the Hybrid model: based on the 2002 input-output tables in the pre-GR period and the 2009 input-output tables in the period of the Great Recession

\begin{tabular}{lcccccccc}
\hline \hline \multicolumn{1}{c}{ Industry } & \multicolumn{3}{c}{ Loadings on $a_{t}$} & \multicolumn{4}{c}{ Loadings on $\eta_{t}$} & \multicolumn{2}{c}{ Loadings on $c_{t}$} \\
& & & \multicolumn{2}{c}{ Pre-GR } & \multicolumn{2}{c}{ GR } & & \\
\cline { 6 - 8 } & $\hat{\lambda}_{i}$ & s.e. & $\widehat{\sigma}_{i}$ & s.e. & $\widehat{\omega}_{i}$ & s.e. & $\widehat{\delta}_{i}$ & s.e. \\
\hline Mining & 2.38 & 0.24 & 2.47 & 0.23 & 1.97 & 0.25 & -0.34 & 0.51 \\
Utilities & -0.18 & 0.58 & 4.56 & 0.36 & 5.64 & 0.46 & 3.29 & 0.71 \\
Construction & 0.68 & 0.28 & 2.45 & 0.20 & 2.89 & 0.25 & -0.57 & 0.39 \\
Durables & 0.86 & 0.26 & 1.32 & 0.12 & 1.01 & 0.13 & 2.80 & 0.30 \\
Nondurables & -0.75 & 0.17 & 1.28 & 0.11 & 1.09 & 0.14 & 1.30 & 0.22 \\
Wholesale & 2.92 & 0.55 & 2.65 & 0.29 & 4.53 & 0.41 & 6.01 & 0.89 \\
Retail & 1.53 & 0.37 & 2.47 & 0.24 & 1.75 & 0.18 & 3.63 & 0.44 \\
Transportation & 0.89 & 0.31 & 2.20 & 0.18 & 1.80 & 0.17 & 3.17 & 0.36 \\
Information & 0.47 & 0.15 & 1.29 & 0.11 & 1.22 & 0.10 & 0.99 & 0.19 \\
Finance & -1.53 & 0.22 & 1.88 & 0.17 & 1.85 & 0.21 & 1.27 & 0.38 \\
Real Estate & 0.74 & 0.14 & 1.18 & 0.10 & 1.11 & 0.10 & 1.00 & 0.21 \\
Professional & 0.32 & 0.07 & 1.10 & 0.09 & 0.66 & 0.05 & 0.37 & 0.10 \\
Education & -0.34 & 0.16 & 1.55 & 0.12 & 1.70 & 0.14 & -0.64 & 0.21 \\
Health Care & 0.14 & 0.08 & 1.51 & 0.12 & 0.52 & 0.05 & -0.62 & 0.08 \\
Recreation & 0.68 & 0.15 & 1.52 & 0.13 & 0.94 & 0.09 & 1.41 & 0.20 \\
Other Services & 0.98 & 0.17 & 1.90 & 0.16 & 1.54 & 0.14 & 0.60 & 0.27 \\
\hline \hline
\end{tabular}

Notes: SE stands for QMLE standard errors. * indicates significance at the $5 \%$ level.

Great-Moderation Two experiments are performed to access the impact of the period of the Great Moderation on the empirical results. The first involves reestimating the factor loadings by starting the pre-GR period in 1984. The results of this experiment are given in the "Experiment 1" column of Table A.8. The empirical results are qualitatively similar to the Hybrid model results presented for the full sample period in Table V, with sectoral shocks still playing a similar role in driving the pre-GR aggregate fluctuations during the period of the Great Moderation.

In the second experiment presented in Table A.8, we estimate a three regime model consisting of the pre-Great Moderation period (1948 to 1983), the Great Moderation period (1984 to 2006) and the Great Recession period (2007 to 2012). To capture the observed reduction in volatility 
Table A.7: Selected summary statistics of the Hybrid model specification in (13): based on the 2002 input-output tables in the pre-GR period and the 2009 input-output tables in the period of the Great recession

\begin{tabular}{|c|c|c|c|c|c|c|c|}
\hline \multirow[b]{3}{*}{ Data } & & \multicolumn{2}{|c|}{ Variability $\left(\sigma_{y}\right)$} & \multicolumn{2}{|c|}{ Avg. Correlation $(\bar{\rho})$} & \multicolumn{2}{|c|}{ Spillover index } \\
\hline & & Pre-GR & GR & Pre-GR & GR & Pre-GR & GR \\
\hline & & 2.69 & 5.23 & 0.26 & 0.45 & & \\
\hline Model & & 2.42 & 5.07 & 0.17 & 0.48 & $50.65 \%$ & $77.32 \%$ \\
\hline & Aggregate & $36.66 \%$ & $8.37 \%$ & & & $22.80 \%$ & $11.83 \%$ \\
\hline & Sectoral & $63.34 \%$ & $12.37 \%$ & & & $27.86 \%$ & $14.50 \%$ \\
\hline & GR & & $79.26 \%$ & & & & $50.98 \%$ \\
\hline
\end{tabular}

Notes: The table shows the standard deviation of aggregate output $\left(\sigma_{y}\right)$, the average pairwise correlation of sectoral growth rates $(\bar{\rho})$ and the Diebold-Yilmaz spillover index for the pre-GR period (1948-2006) and the GR period (20072012), for the data and for the model. The model is based on the hybrid specification in (13) where the 2002 input-use table is used for $\Gamma$ before 2007 and the 2009 input-use table is used after 2007. Volatility of aggregate output for the data and model are based on constant weights over the period 1948 to 2016.

during the Great Moderation period, a parsimonious parameterization is adopted whereby the sectoral loadings during this period are the loadings for the pre-Great Moderation period scaled by an additional parameter. Letting $T_{0}$ correspond to the pre-Great Moderation period, $T_{1}$ now representing the period of the Great Moderation prior to the Great Recession and as before $T_{2}$ representing the Great Recession period, the factor structure in (4) for the two-regime model is respecified as

$$
\begin{array}{lll}
\varepsilon_{i t}=\lambda_{i} a_{t}+\sigma_{i} \eta_{i t} & : & t \in T_{0}, \forall_{i}, \\
\varepsilon_{i t}=\lambda_{i} a_{t}+\sigma_{i}(1+\tau) \eta_{i t} & : & t \in T_{1}, \forall_{i}, \\
\varepsilon_{i t}=\lambda_{i} a_{t}+\omega_{i} \eta_{i t}+\delta_{i} c_{t} & : & t \in T_{2}, \forall_{i} .
\end{array}
$$

The factor decompositions from estimating the 3-regime model are presented in Table A.8. The key result is that sectoral shocks still play a dominating role both during and prior to the Great Moderation in determining aggregate volatility. In addition, the contribution of the GR factor during the Great Recession is $77 \%$ which is very similar to its contribution of $75 \%$ reported for the two regime Hybrid model in Table $\mathrm{V}$.

Dating the Onset of the Great Recession To determine the sensitivity of the estimated factor loadings to this choice of starting date Table A.9 gives information criteria summary statistics of the estimated Hybrid model for 6 alternative crisis starting dates beginning with 2007Q1 which has been the initial choice adopted in the empirical analysis so far, and ending with 2008Q2 in steps of one quarter. A comparison of the information criteria shows that the crisis starts in early 2008 with the HIC statistic choosing the second quarter and the SIC statistic choosing the first. Moreover, Figure A.2 shows that the factor loading estimates are insensitive to the changes in the starting dates showing that the empirical results are robust to alternative choices of date.

How Special is the Great Recession? The final robustness check is based on a placebo test to determine if the important role of the second common factor in driving aggregate volatility is solely a characteristic of the Great Recession or whether is a feature of other crisis periods. The approach is to (1) compute the average cross-sectoral correlation of output growth and (2) re-estimate the 
Table A.8: Including the Great Moderation period in the Hybrid SVAR factor structure

\begin{tabular}{lcccccc}
\hline \hline & \multicolumn{2}{c}{ Experiment 1 } & & \multicolumn{3}{c}{ Experiment 2 } \\
\cline { 2 - 3 } \cline { 6 - 7 } & $\begin{array}{c}\text { Great } \\
\text { Moderation } \\
(1984-06)\end{array}$ & $\begin{array}{c}\text { Great } \\
\text { Recession } \\
(2007-12)\end{array}$ & & $\begin{array}{c}\text { Pre-Great } \\
\text { Moderation } \\
(1948-83)\end{array}$ & $\begin{array}{c}\text { Great } \\
\text { Moderation } \\
(1984-06)\end{array}$ & $\begin{array}{c}\text { Great } \\
\text { Recession } \\
(2007-12)\end{array}$ \\
\cline { 2 - 3 } Data $\left(\sigma_{y}\right)$ & 2.03 & 5.23 & & 3.03 & 2.00 & 5.23 \\
& & & & & 2.00 & 4.81 \\
Model $\left(\sigma_{y}\right)$ & 3.19 & 4.42 & & 2.31 & & \\
Aggregate & $66.60 \%$ & $34.66 \%$ & & $19.13 \%$ & $25.51 \%$ & $4.39 \%$ \\
Sectoral & $33.40 \%$ & $17.38 \%$ & & $80.87 \%$ & $74.49 \%$ & $18.53 \%$ \\
GR & & $47.96 \%$ & & & $77.08 \%$ \\
\hline \hline
\end{tabular}

Notes: Experiment 1 is based on estimating the Hybrid model with the pre-GR period beginning in 1984 corresponding to the start of the Great Moderation period. Experiment 2 involves estimating a three regime model consisting of the pre-Great Moderation period (1948 to 1983), the Great Moderation period (1984 to 2006) and the Great Recession period (2007 to 2012) based on the factor structure given in (39). Volatility of aggregate output for the data and model are based on constant weights over the period 1948 to 2016.

Table A.9: Model summary statistics for alternative starting dates of the Great Recession

\begin{tabular}{ccccccc}
\hline \hline Statistic & \multicolumn{6}{c}{ Great Recession Starting Dates } \\
\cline { 2 - 7 } & $2007 \mathrm{Q} 1$ & $2007 \mathrm{Q} 2$ & $2007 \mathrm{Q} 3$ & $2007 \mathrm{Q} 4$ & $2008 \mathrm{Q} 1$ & $2008 \mathrm{Q} 2$ \\
\hline HIC & 139.84 & 139.32 & 139.28 & 139.11 & 138.71 & 138.69 \\
SIC & 141.28 & 140.77 & 140.74 & 140.59 & 140.20 & 140.21 \\
\hline \hline
\end{tabular}


Figure A.2: Estimated sectoral loadings for alternative starting dates of the Great Recession.
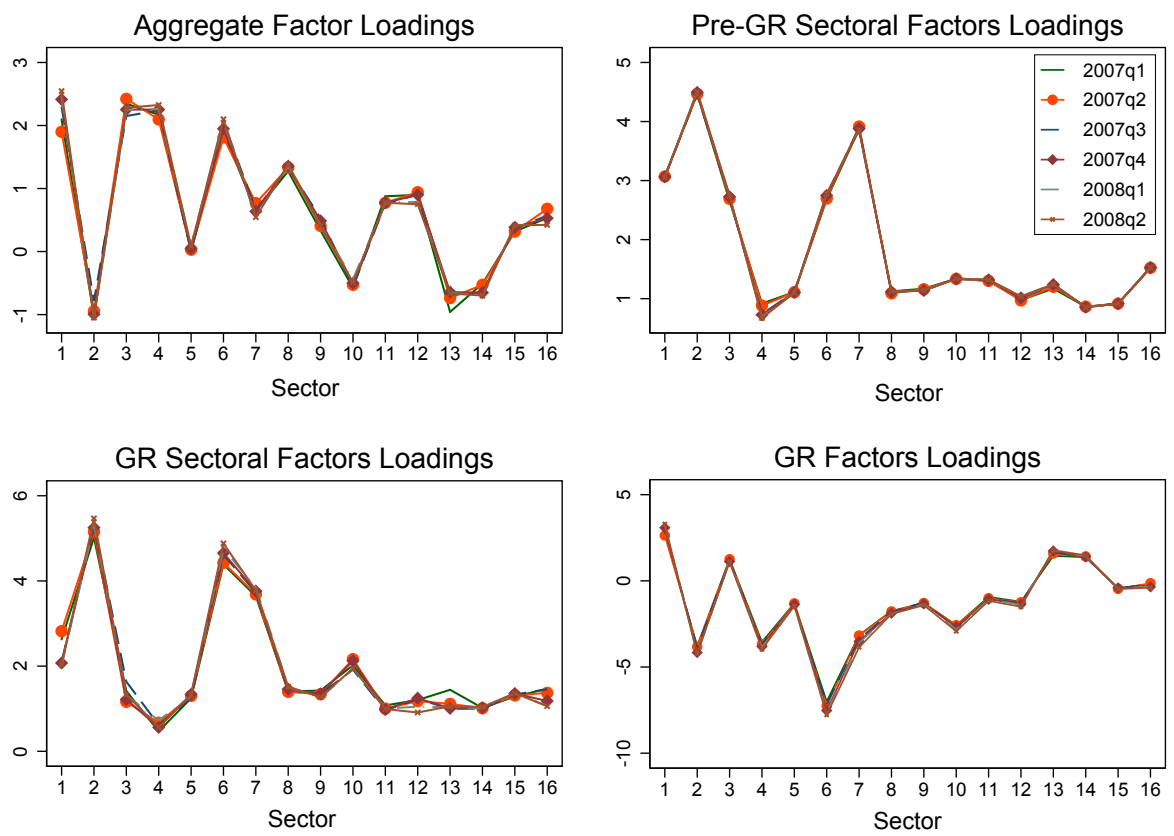

Notes: This figure shows the estimates of loadings for the aggregate factor, the sector-specific factor before and during the Great Recession, and the GR factor, using different dates as the onset of the Great Recession.

Hybrid model whereby a second common factor occurs based on a six-year rolling window from $[1950,1955]$ to $[2010,2015]$ in steps of one year. The results are reported in Figure A.3, which plots the rolling correlation and the estimated share contribution of a second common factor against the middle year of the rolling window (i.e. year $t+2$ of the window $[t, t+5]$ ). Although recessions generally appear to be times of heightened co-movement in most cases as suggested by the dynamics of the cross-sectoral correlations, they are not necessarily associated with a significant contribution from a second common factor. The Great Recession is in sharp contrast with the previous recessions in that it experiences dramatic increases in both the corss-correlations (of almost $60 \%$ on average) and the contribution from the second common factor reaching a maximum of over $70 \%$. 
Figure A.3: Cross-correlation and the contribution from the additional common factor

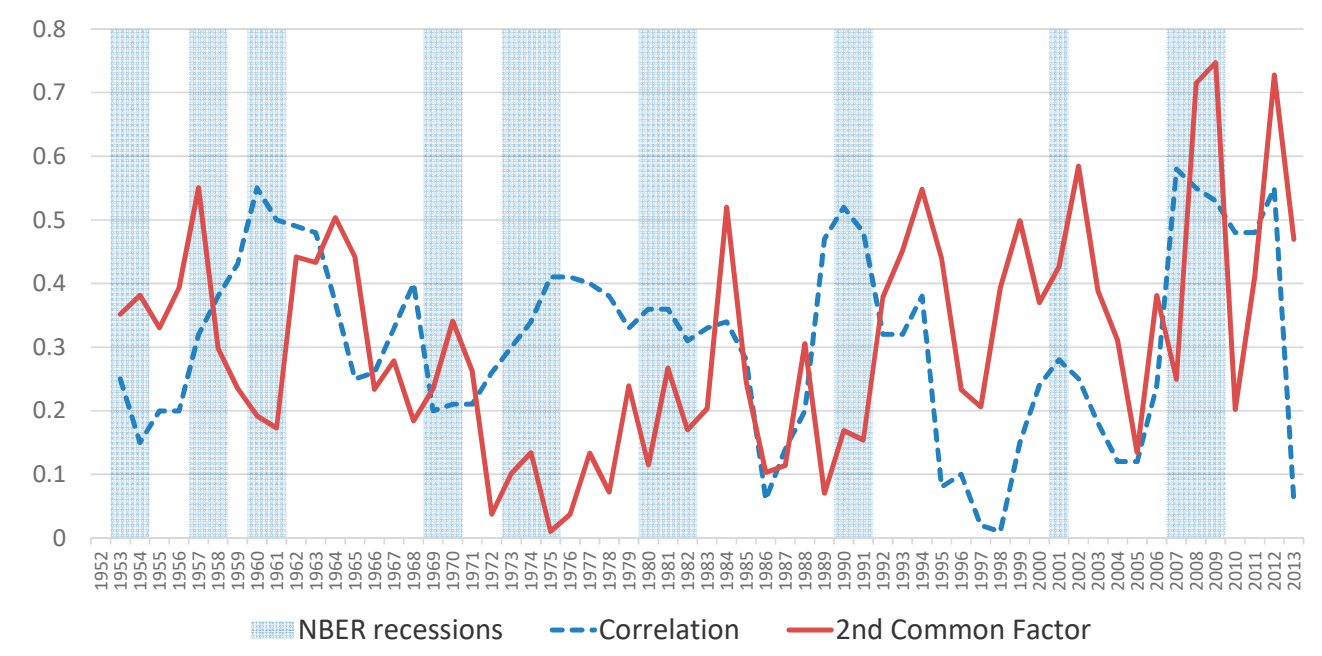

